Review

\title{
Current Status and Future Trends in the Operation and Maintenance of Offshore Wind Turbines: A Review
}

\author{
Giovanni Rinaldi ${ }^{1, * \mathbb{D}}$, Philipp R. Thies ${ }^{1} \mathbb{D}$ and Lars Johanning ${ }^{1,2} \mathbb{D}$ \\ 1 Renewable Energy Group, Penryn Campus, University of Exeter, Treliever Road, Penryn, \\ Cornwall TR10 9FE, UK; p.r.thies@exeter.ac.uk (P.R.T.); 1.johanning@exeter.ac.uk (L.J.) \\ 2 College of Shipbuilding Engineering, Harbin Engineering University, Harbin 150001, China \\ * Correspondence: g.rinaldi@exeter.ac.uk
}

check for updates

Citation: Rinaldi, G.; Thies, P.R.; Johanning, L. Current Status and Future Trends in the Operation and Maintenance of Offshore Wind Turbines: A Review. Energies 2021, 14, 2484. https://doi.org/10.3390 /en14092484

Academic Editor: Ricardo J. Bessa

Received: 10 March 2021

Accepted: 21 April 2021

Published: 27 April 2021

Publisher's Note: MDPI stays neutral with regard to jurisdictional claims in published maps and institutional affiliations.

Copyright: (c) 2021 by the authors. Licensee MDPI, Basel, Switzerland. This article is an open access article distributed under the terms and conditions of the Creative Commons Attribution (CC BY) license (https:// creativecommons.org/licenses/by/ $4.0 /)$.

\begin{abstract}
Operation and maintenance constitute a substantial share of the lifecycle expenditures of an offshore renewable energy farm. A noteworthy number of methods and techniques have been developed to provide decision-making support in strategic planning and asset management. Condition monitoring instrumentation is commonly used, especially in offshore wind farms, due to the benefits it provides in terms of fault identification and performance evaluation and improvement. Incorporating technology advancements, a shift towards automation and digitalisation is taking place in the offshore maintenance sector. This paper reviews the existing literature and novel approaches in the operation and maintenance planning and the condition monitoring of offshore renewable energy farms, with an emphasis on the offshore wind sector, discussing their benefits and limitations. The state-of-the-art in industrial condition-based maintenance is reviewed, together with deterioration models and fault diagnosis and prognosis techniques. Future scenarios in robotics, artificial intelligence and data processing are investigated. The application challenges of these strategies and Industry 4.0 concepts in the offshore renewables sector are scrutinised, together with the potential implications of early-stage project integration. The identified technologies are ranked against a series of indicators, providing a reference for a range of industry stakeholders.
\end{abstract}

Keywords: offshore renewable energy; O\&M planning; condition monitoring; condition-based maintenance; SCADA; fault diagnosis/prognosis; floating wind; digitalisation; soft sensors; robotics; Industry 4.0

\section{Introduction}

The offshore wind sector has grown significantly over recent years, reaching a total of 29.1 GW (over 10\% of global wind installations) [1]. Previous experience with onshore wind turbines, combined with noteworthy investments, has allowed offshore wind to become one of the most viable and profitable ways of generating electricity [2]. Besides, in order to exploit stronger and more stable winds and to overcome the limitations related to the use of seabed-fixed foundations, there is a growing interest in floating offshore wind [3]. With offshore wind turbines at a mature stage, and considered reliable and consolidated machines, the margins for enhancement of the technology itself and of already installed turbines themselves are becoming increasingly limited. Nonetheless, there is a necessity to operate and maintain these assets efficiently and effectively, allowing them to reach high levels of availability and productivity.

Operation and Maintenance (O\&M) has been recognised as one of the main contributors to the overall cost of energy, typically amounting to 25-30\% of the lifecycle costs [4]. Production losses due to downtime over 20 years of operation have been estimated at around $12 \mathrm{~m} €$ /year for a $500 \mathrm{MW}$ offshore wind farm situated $50 \mathrm{~km}$ offshore in the North Sea [5]. Assuming this would be representative for other sites, the average annual production loss would be $€ 24 \mathrm{k} / \mathrm{MW}$. Therefore a suitable trade-off that allows us to keep the farm availability high while maintenance costs remain low is required [6]. To 
achieve this goal, a decision maker, such as an ORE farm operator, can generally act on two main aspects of the farm management: (i) the reliability and maintainability of the devices, e.g., number of interventions and redundancy measures, or (ii) the supportability, e.g., choice of the most suited vessels or helicopters and allocation of related routing and technicians.

This work mainly focuses on the first aspect, i.e., the maintenance of the components and subsystems of an ORE asset. The aim of the paper is to provide a holistic and exhaustive overview of the currently available methods and techniques, as well as identify future trends in the ORE O\&M sector. For this scope, established maintenance strategies usually available for ORE devices are reviewed. Health monitoring, diagnosis and prognosis methods, which together open the way to condition-based maintenance, are addressed. Maintenance practices in other industries are reviewed to explore the extent of knowledge transfer to the ORE sector. Recent efforts at and future trends towards automation and digitalisation of the maintenance tasks for offshore assets are investigated and discussed.

This work is of interest to a wide audience in both the academic and industrial ORE sectors. The investigation covers all ORE technologies, but focuses on the offshore wind sector, both fixed and floating.

The main objectives of this work are:

- to provide an overview of the different aspects of ORE maintenance for early inclusion in the planning of offshore renewables O\&M;

- to review and summarise the advancements in maintenance planning in other industries in order to identify synergies for the ORE sector;

- to expand the existing literature on condition monitoring and condition-based maintenance for ORE to the novel floating offshore wind (FLOW) sector;

- to assess current efforts towards automation and digitalisation, providing a detailed impression of the opportunities and challenges in applying Industry 4.0 concepts to the offshore maintenance sector.

The main contribution of this paper is to enable the integration of state-of-the-art O\&M methods at an early stage of offshore wind installations, utilising industrial condition-based maintenance deterioration models, fault diagnosis/prognosis techniques, as well as recent advances in robotics, artificial intelligence and data processing. In addition to existing review papers, the present work explores future trends and looks across other industries to investigate the transferability of the identified techniques.

The rest of the paper is structured as follows. The research methodology, describing criteria for the review process, is outlined in Section 2. Offshore O\&M and relevant aspects, including computational tools, condition monitoring techniques, deterioration models and novel approaches, are reviewed in Section 3. In Section 4, maintenance techniques and methodologies currently applied in other industries are investigated to explore knowledge transfer possibilities for the ORE sector. Findings are discussed from different stakeholder perspectives in Section 5, and a ranking of the different techniques is provided. Conclusions and proposals for future work are provided in Section 6.

\section{Research Methodology}

The overall approach follows the principles of industrial maintenance management [7]. While knowledge about both the offshore O\&M sector and modern industry maintenance practices is available, their combination is hardly applied or documented. An initial scoping study was used to narrow the area of investigation and define the relevant keywords for the search terms. Web-based search engines and databases were used to pursue relevant documentation, by exploiting the identified keywords and Boolean operators. No exclusions were imposed on the time of publication, but preference was given to the most recent results. Selection of pertinent (based on the experience of the authors in industrial projects) items (journal and conference papers, public reports, project deliverables, webpages) was made according to their relevance to the topics treated in this paper. The investigation enabled prioritisation of the key areas in relation to the potential technical and economic 
impacts, on O\&M, of offshore renewable devices. The research methodology is graphically summarised in Figure 1.

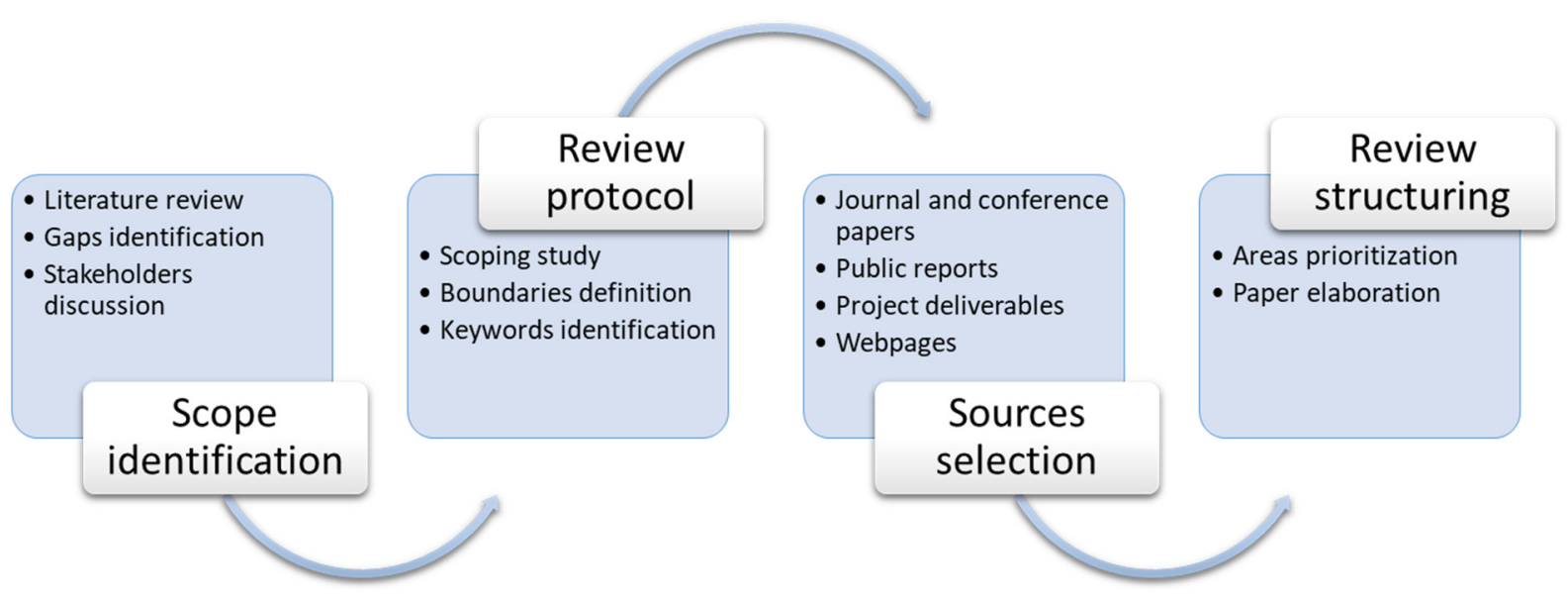

Figure 1. Overview of the systematic literature review protocol.

\section{Operation and Maintenance of Offshore Renewable Energy Farms}

In industry, O\&M denotes a set of procedures which, following the installation and commissioning of a system, aim to keep it operational for a desired length of time under economic constraints [8]. The main goal of maintenance is to allow a system to perform its intended functions with the minimum resources required to ensure that the functions are as specified, ensuring reliability and the capacity to recover from breakdowns [9].

$\mathrm{O} \& \mathrm{M}$ costs can be either fixed or variable. Among fixed costs are regular device checks and tests, as well as insurance costs, use of facilities (e.g., spare parts warehouse) and expenses needed to ensure that health and safety requirements are met. In contrast, variable costs change based on the number of operations, as well as unpredicted or unscheduled interventions. In this work, maintenance is used to indicate a generic intervention aiming at restoring an item to its functioning state, e.g., a repair or a replacement.

\subsection{Maintenance Strategies}

Maintenance, assets management, scheduling techniques and optimisation approaches are all interconnected topics which have been extensively investigated [8-11]. A comprehensive review and classification of maintenance policies is provided in [12]. A simple classification of maintenance philosophies considers three main branches: corrective, periodic and condition-based [13]. Usually, a combination of these strategies is applied: corrective strategies for assets with low criticality (both in terms of cost and system reliability), periodic strategies for assets with a well-known and consistent failure-time correlation, and condition-based strategies for the most critical assets [14]. A complete comparison of maintenance methods, showing the advantages and disadvantages of each strategy, is provided in [15]. In other classifications, predictive and proactive maintenance are distinguished $[16,17]$. These can be considered as model-driven or condition-based, respectively. While both aim at increasing the components' life and availability, the first exploits historical data and stochastic models, whereas the second relies on continuous monitoring to detect early signs of failure. This is an important distinction, which asset managers have to be aware of in order to pursue suitable O\&M strategies.

A graphical summary of the main maintenance categories is shown in Figure 2. 


\section{Maintenance strategies}

\section{Corrective}

(for non-critical components)

Immediate
$\begin{gathered}\text { (subject to asset } \\ \text { availability) }\end{gathered}$

(postponed due to lack of resources)

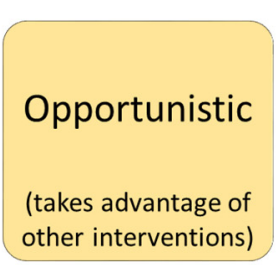

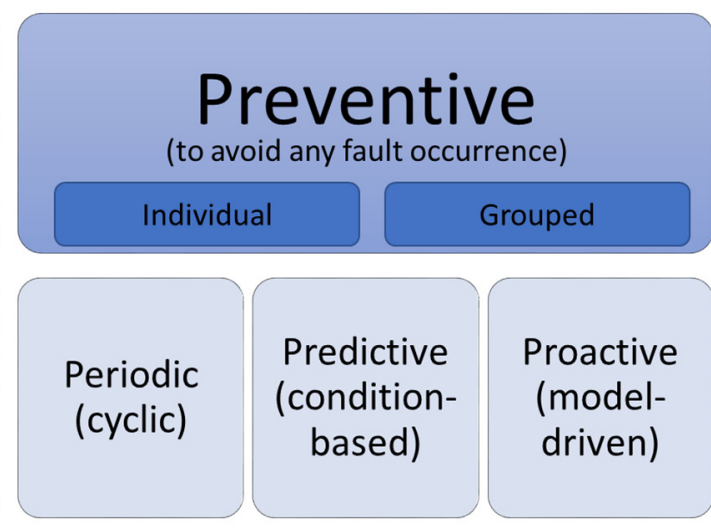

Figure 2. Categories of maintenance. Adapted from $[18,19]$.

When multiple components or systems are considered, two further approaches can be distinguished: group and opportunistic maintenance [20,21]. In the former, multiple interventions are scheduled to happen at the same time; for instance, a group of components has to be maintained simultaneously. In the latter, maintenance is extended to other systems because it is convenient for technical or economic reasons, for example, to take advantage of a repair in another component. In a sense, group maintenance is planned in advance, while opportunistic maintenance arises from the required intervention.

\subsection{Computational Tools for OEM Planning}

A large number of simulation tools have been developed in recent years to optimise the O\&M planning of ORE farms and provide asset management support. Most tools simulate the dynamics of the farm over a certain period, typically the project lifetime, and analyse different aspects in order to identify bottlenecks in the O\&M strategy and suggest possible areas for improvement. Each tool can be individually developed to capture one or multiple aspects of the farm logistics, as well as to span multiple planning horizons [22]. While some tools are limited to the characterisation of the project, generally through the estimation of its key performance indicators (KPIs), other tools include optimisation features [23]. A characterisation tool can be used as a first step to understand the asset performance and to prioritise actions for KPI improvement. A graphical representation of the inputs, constraints, mechanisms and outputs typically considered in an offshore O\&M simulation tool is provided in Figure 3 [24-26]. Inputs and constraints include the specifications of the project, both for the single device and for the entire farm, and of the maintenance assets. Mechanisms define the rules for the simulation of the O\&M activities. Outputs provide a technical and economic assessment of the project during the simulated period.

Comprehensive reviews of O\&M simulation tools are presented in [27-30]. These are reviewed and catalogued according to their purpose, characteristics, working principle and underlying methodology. As offshore wind is the most mature technology among ocean renewables, most of the tools have been developed specifically for this technology [19]. Nonetheless, many of these O\&M models are flexible or can be easily adapted to other marine renewables [25]. 


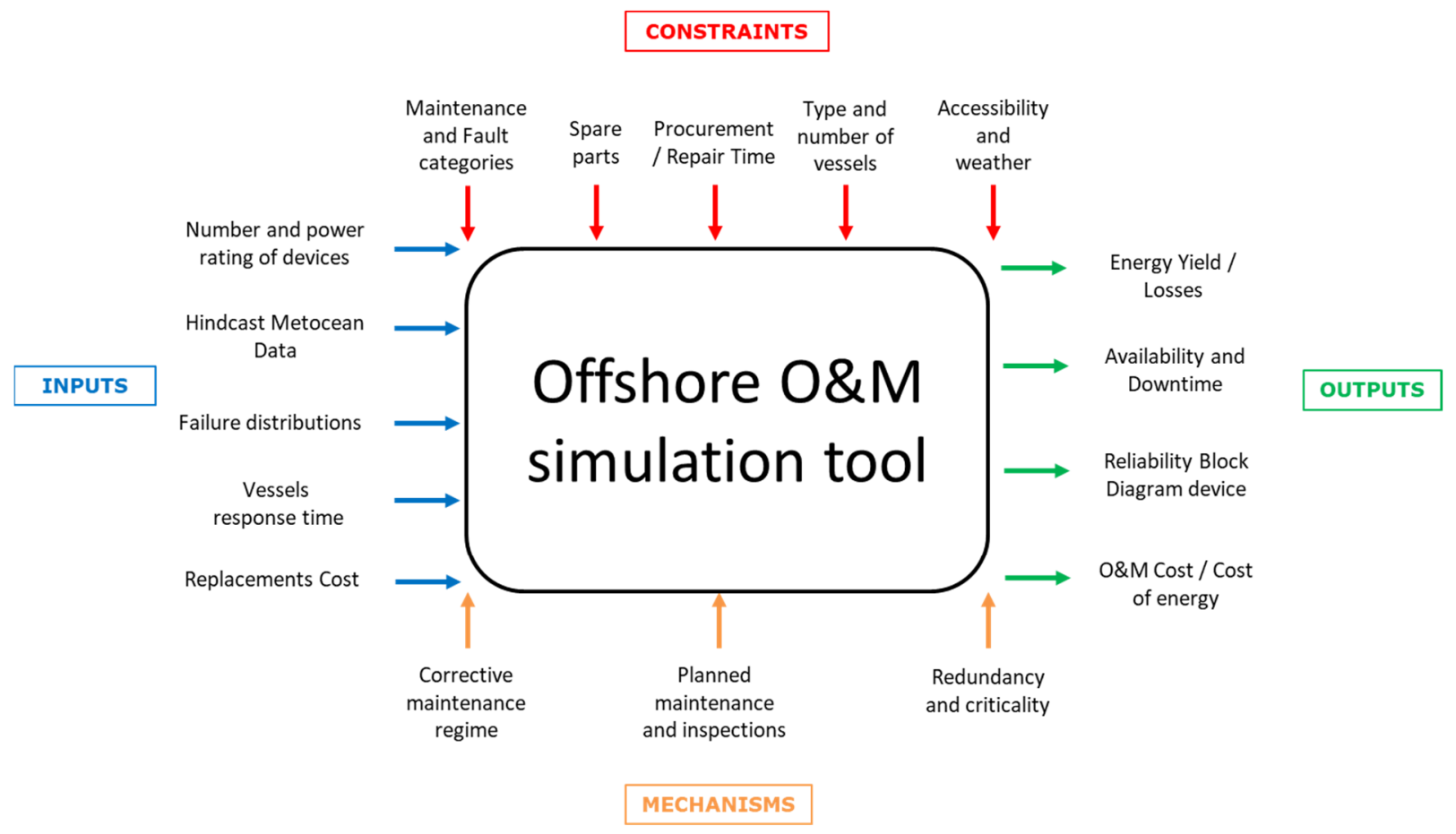

Figure 3. Summary of the typical inputs, constraints, mechanisms and outputs considered in an offshore O\&M tool. Adapted from [24-26].

An important aspect related to the use and exploitation of simulation tools for O\&M planning is the procurement of suitable and representative reliability data. This process is especially challenging in the ORE sector due to the relative novelty of and limited experience with the devices. A collection of the initiatives which are aimed at collecting performance and reliability data of both onshore and offshore wind turbines, together with the related outcomes, is provided in [31].

\subsection{Condition-Based Maintenance and System Dependencies}

Condition-based maintenance (CBM) is an approach focused on the combination of data-driven reliability models with data collected from sensors and condition monitoring (CM) systems in order to develop improved O\&M strategies [15]. Using the data produced by sensors and the knowledge accumulated with historical data, predictive and proactive maintenance can be planned. The idea is to intervene only when required, i.e., neither in advance, when the component is still in a good state, nor too late when the component has already failed and is causing downtime. The main steps of CBM are:

1. Data collection from $\mathrm{CM}$ systems and subsequent signal processing to extract relevant information. This includes fault diagnosis;

2. Reliability modelling to capture deterioration and predict failures. This includes fault prognosis and subsequent verification with the existing dataset;

3. Decision making towards maintenance optimisation. This includes inspection and preventive maintenance schedules.

This framework is graphically summarised in Figure 4.

Thus, CBM relies on the combined exploitation of data collected from sensors and monitoring instrumentation with calibrated reliability models in order to support maintenance scheduling. The objective of CBM is to obtain clear, specific and timely indications about when maintenance is actually required, i.e., the optimal preventive replacement threshold [16]. Alternatively, the focus of CBM can be on the optimal inspection schedule. In this way, early or delayed interventions, and unnecessary operations or downtime, are reduced, and unexpected failures avoided. In this regard, even if the component can be monitored continuously, intervening for maintenance or inspection might be possible only 
at discrete intervals [32]. In these cases, it is useful to distinguish between periodic and aperiodic decision moments.

PHASES

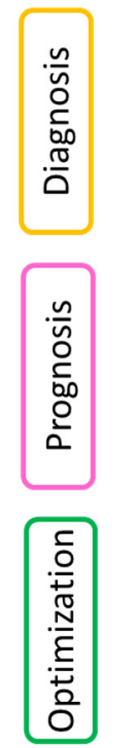

PROCESS

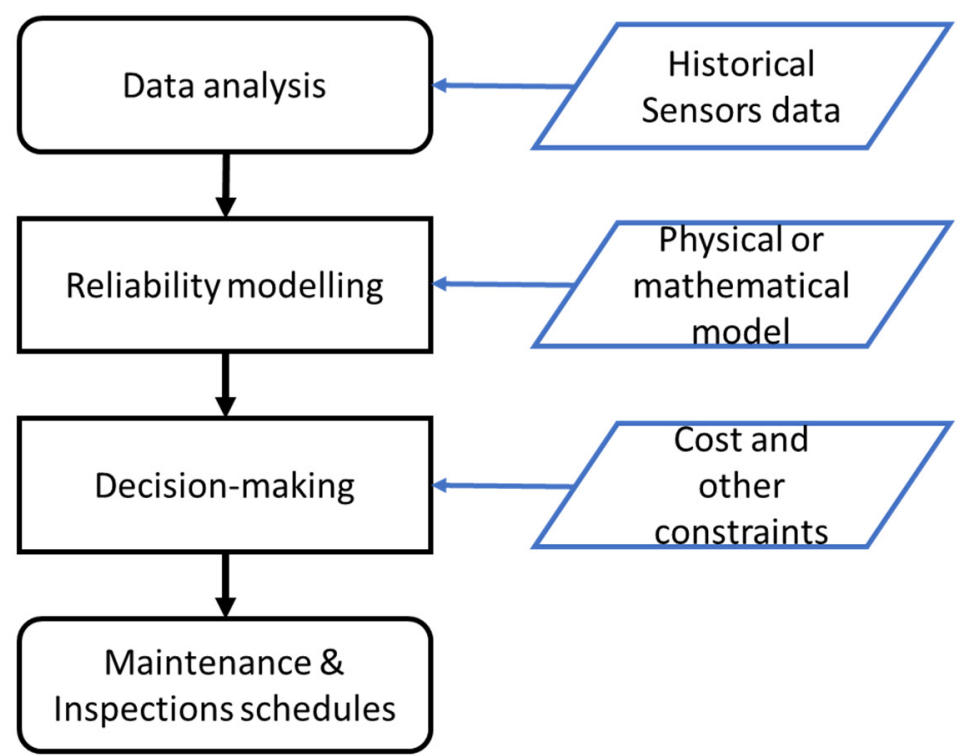

Figure 4. Simplified flowchart of a condition-based maintenance framework.

The downside is that CBM requires a thorough understanding of multi-system dynamics, especially in terms of interdependent failures, as well as the environmental conditions and related loads and consequences [17]. Moreover, CBM is a complex process because it involves the implementation of several tasks, i.e., sensor installation, data management (acquisition, transmission, processing), asset health assessment and decision making.

In offshore maintenance, CBM is pivotal due to a series of factors [33]: intermittent and strong operating loads, corrosive environment, wind gusts, extreme waves, distance from shore, biofouling and high capital cost. In some cases, when a farm contains a large number of devices, a subset of these, considered representative of the entire farm, can be selected for detailed inspection rather than examining all the devices [34].

A large number of reviews on CBM features, policies and classifications exist in the literature [21,35-52]. A comprehensive review of CBM approaches for offshore applications, focusing especially on induction machines and drive trains, is presented in [47]. Alaswad et al. [48] classify CBM models into three classes: discrete, continuous and proportional hazard model (PHM).

In its simplest form, CBM focuses on each component individually, based on the assumption that failures and degradation phenomena are independent. However, this is a simplification that might lead to the incorrect estimation of the degradation state or time to failure. Dependencies between components can be very different $[32,50]$ and can be summarised as follows (see also Figure 5):

- Structural or functional dependence-a component stops functioning as a consequence of another dependent component stopping due to failure (technical) or maintenance (performance). In this case, maintenance on the non-dependent component might be required pre- or post-intervention on the dependent component;

- Stochastic dependence-the deterioration of one component has an effect on other components. Common ways in which this can happen are a direct fault (failureinduced damage), due to an increase in the workload shared until that moment (load sharing) and mutual (common-mode) deterioration [32]. In this case, the degradation of dependent components can be modelled using a joint probability distribution [51]; 
- Economic dependence-maintenance for multiple components is either cheaper (positive economic dependence) or more expensive (negative economic dependence) than maintaining the same components individually;

- Resource dependence-maintenance is constrained by a limited amount of a certain resource, e.g., spare parts, tools and technicians.

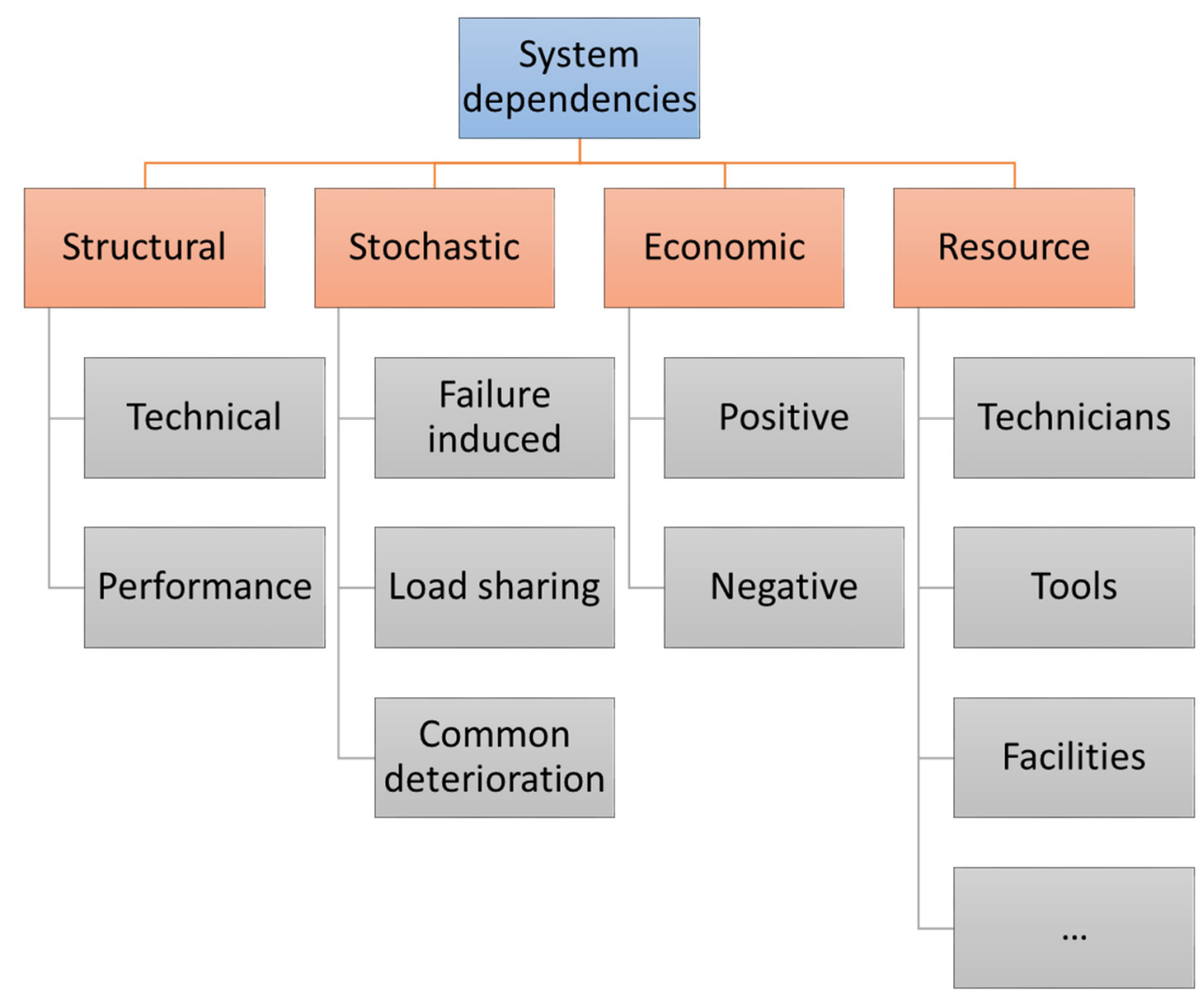

Figure 5. Types of component dependencies. Adapted from [32,50,51].

Thus, dependencies may lead to secondary effects such as cost minimisation or service life reduction. For this reason, an appropriate opportunistic maintenance might not necessarily be periodic [12]. Inspections may support the schedule of interventions by revealing the status of a component. However, two issues have to be considered in this respect. Firstly, inspections can be imperfect (i.e., fail to detect a fault). Secondly, inspections themselves have to be scheduled appropriately following similar criteria to those of maintenance optimisation, i.e., costs minimisation or reliability maximisation. In contrast to continuous monitoring, inspections can be intermittent, either regular or irregular, and this decision as well as the exact interval may vary as the system ages [21]. Thus, inspection schedule optimisation is a relevant aspect of the overall O\&M planning, and decision models can be used to fulfil this purpose [22].

\subsection{Condition Monitoring, Structural Health Monitoring and SCADA Systems}

Condition monitoring $(\mathrm{CM})$ observes one or more parameters that are representative of the "health" or condition of the machinery/system, such that a significant change is indicative of a developing failure [52]. CM allows for the early detection of failure mechanisms, allowing for a decrease in human inspections and the timely scheduling of maintenance interventions. Sensors and CM instrumentation are used to collect data, which are then transmitted through a communication network for storage and processing. These data are then used for analytics, decision-making support, diagnosis and prognosis, and optimisation. Sensors, together with actuators and communication systems, are one of the 
key components of modern infrastructures such as the Internet of Things (IoT) discussed in Section 4.

Traditionally, a number of non-destructive testing (NDT) techniques have been employed in ORE CM to monitor both operational and environmental parameters. These include, but are not limited to [53-58]:

- Vibration analysis. Exploits accelerometers and piezoelectric or micro-electromechanical systems (MEMS) to monitor the drivetrain, gearbox and bearings;

- Oil quality analysis and oil particle counters. To monitor lubrication status in mechanical components;

- Acoustic emissions. To detect possible flaws and imperfections during operation, such as cracks, impacts or excessive deformations;

- Ultrasonic testing. To reveal possible cracks and assess the interior structures of components like blades, tower and support structure;

- Temperature analysis and thermography. To detect thermal fluctuations or anomalies in both mechanical and electrical components;

- Modal Properties Monitoring. To assess possible changes in mass or stiffness of the structural components which can affect modal parameters such as damping coefficient and resonance frequency. It is achieved by means of accelerometers that monitor the dynamic response of the structure, or piezoelectric materials which can detect structural damage;

- Humidity analysis. To characterise the level of moisture in the air and assess eventual corrosion hazards;

- Strain measurement. To measure bending and length variations in blades and other structural components using fibre-optic or strain gauges, since these can affect the stresses and loads on the materials;

- Electric signals measurement. It includes time and frequency domain analysis of the electric power, voltage and current. These measurements are used to make sure that the farm complies with the grid requirements and the energy transmission is stable. This ensures a high-quality power generation and preserves peripheral systems, e.g., substations. But it can also be used to detect mechanical faults, e.g., in the generator.

Nonetheless, the integration of these techniques (and the measured information) to obtain useful, efficient, cost-effective and smart maintenance plans is a significant challenge. Similarly, suitable communication links should be implemented to guarantee the reliable transmission of the measurements. Examples of possible communications links are fibre optics integrated into electrical cables, radio or GSM connections (depending on the distance from shore) and satellite link connections. To ensure redundancy, at least two communication paths should be implemented, especially for critical reliability indicators.

Structural health monitoring (SHM) is a branch of $\mathrm{CM}$, dedicated to monitor the integrity of structural components by means of specific sensors. It can prevent catastrophic failures, with serious consequences for the safety of the personnel and the environment. Moreover, it deals with components whose repair or replacement involves great costs, and aims at ensuring that the device does not suffer breakdowns for its entire service life (this may also include Life Time Extension (LTE)). The main factors that affect structural faults for ORE devices are fatigue, extreme loads (e.g., wind gusts), lightning strikes and corrosion [59]. A thorough review of SHM techniques and sensors for structural components of offshore wind turbines can be found in [57,60-65], with details of signal and processing methods in [65] and guidelines on LTE and end-of-life solutions in [62].

A condition monitoring system must be able to meet the following demands [15]:

- High degree of modularity

- If possible, plug and play

- Use of open standards

- Ease of configuration

- Generic solution for module configuration

- Generic interfaces for modules/data 
- Platform independence

- Modern software architecture

- Possible remote software updates

- Many levels of access and security

- Self-starting and stable

For this reason, CM instrumentation can include thousands of sensors, which cause additional capital cost due to the purchase, installation and maintenance of the equipment. The cost of $\mathrm{CM}$ instruments alone for a single wind turbine has been estimated at $€ 20,000$ [66]. However, despite being case-specific, the cost-effectiveness of implementing a CM system has been aptly demonstrated $[52,67,68]$. CM instrumentation can reduce the cost due to unnecessary inspections, and therefore contribute towards a higher profitability [53]. In [67], lifetime savings between $£ 11$ and $20 \mathrm{~m}$ are estimated for different combinations of CM and SHM over a strategy exclusively based on preventive maintenance (for 20 OWTs of $3 \mathrm{MW} 13 \mathrm{~km}$ offshore during 20 years). Although CM instrumentation can be applied to almost any component, the main focus is usually on the most critical ones, i.e., those generating long downtimes or high repair/replacement expenses in case of failure.

Signal and alarms from CM instrumentation, together with real-time power performance and environmental parameters, are collected by the so-called supervisory control and data acquisition (SCADA) system. Raw SCADA data are processed to organise the information and create reports and dashboards which inform on the device performance. Apart from failure logs, the collected parameters typically include environmental conditions (e.g., wind speed, relative humidity, ambient temperature, turbulence) and device information (e.g., rotor and generator speeds, lubrication state, currents and voltages, generated power or downtime due to failure). Hundreds of signals can be collected for each device. The frequency of data collection is typically five or ten minutes, eventually with records averaged over this interval and related statistical measures. From the device, the information is transmitted via an appropriate telecommunication network. The use of SCADA systems to derive O\&M indications and complement historical failure databases is documented in [69-73].

The CM and SCADA systems are components themselves, and thus subject to failure or communication loss. A consequence of this problem is that sometimes a part of the dataset is missing or corrupted, with possible repercussions on data analysis and model training. One possible solution is to omit the missing data from the model and continue the analysis with the available data, but this might lead to erroneous or biased results. Several methods have been proposed to fill the gaps and aid the reconstruction of the full dataset [74]. Guidelines, practical aspects, potential and limitations of SCADA and purpose-designed CM systems are provided in [19,56,75-80]. Review papers describing the state-of-the-art in CM systems include [56,67,81-83]. A thorough review of the approaches available to detect anomalies in wind turbines data is provided in [72,84].

\subsubsection{Offshore Wind}

Since offshore WTs, except a few exceptions, show limited failures associated exclusively with the offshore environment (e.g., sea spray), the $\mathrm{CM}$ techniques used for onshore WTs can also be applied to offshore WTs [53].

Here, CM systems are typically applied to the main components, i.e., tower, blades, gearbox, generator and bearings. However, the number of sensors and their position can vary, as well as the data acquisition and signal processing technique [81]. A suitable arrangement is needed in order to capture failures of various nature, e.g., structural, mechanical, electrical or material.

Guidelines on prioritisation of the systems and parameters to be monitored in an offshore wind project to maximise the CM value are provided in [18]. These are based on the outcomes of 12 FMECA workshops with experts from companies representing about $70 \%$ of the European installed capacity. According to the paper, due to the efforts required 
in implementing a CBM strategy, it is advisable to prioritise components and failure modes following a risk-based approach. Similarly, useful approaches and techniques to support OWT maintenance scheduling are provided in [82]. Here, field data coming from sensors and CM instrumentation are defined as "product use information", and Big Data analytics (described in Section 4.4) is used to extract as much indications as possible.

\subsubsection{Floating Offshore Wind}

According to [83], as of today there are no publicly documented commercial applications on CM for floating wind turbines. This is mainly due to the fact that the technology is still at a lower level of development when compared to its bottom-fixed counterpart. As such, it is likely that the condition monitoring instrumentation will change as the development continues according to the technology readiness level (TRL). For example, a series of sensors required during the testing phase (e.g., TRL 3-5) or one full-scale prototype (TRL 5-7) may not be needed for the final project with the final version of the technology because its behaviour at that stage is already known and the device has been optimised accordingly. As a result, the monitoring instrumentation might be reduced or modified depending on the requirements at each stage of development.

However, the floating nature of the platform will bring about a series of new requirements, such as additional environmental parameters to monitor, e.g., hydrodynamic loadings and platform motions. While corrosion is expected to cause known problems, fatigue due to wave and wind loadings has to be assessed in view of the floating nature of the platform, especially in regard to the tower and foundation/mooring failure mechanisms. An increased use of control systems to monitor the platform motions will also lead to a higher number of electrical and power electronics-related failures.

The increasing power rates of wind turbines for offshore applications will cause a direct increase of the size, and therefore mass, of the wind turbine components. This will pose new challenges to the structural integrity of the floating foundation. Similarly, as the distance from shore increases, challenges to the installation and operation of CM and SHM instrumentation become more relevant.

A methodology for the risk assessment and management of substructures for deep water floating WTs is provided in [84], while a complete assessment of the criticality of novel floating offshore wind components is presented in [85]. The FLOTANT project [86], among other innovations, includes an improvement of the O\&M strategy for floating wind projects. This relies on a combination of sensing solutions, computational assessment and multi-objective optimisation in order to provide holistic decision-making support.

\subsubsection{Other Marine Renewables}

Other marine renewables (i.e., wave and tidal energy converters) can benefit from the use of sensors and predictive models to advance towards a condition-based maintenance strategy. As for the O\&M simulation tools, most of the CBM methods and techniques applicable to offshore wind can be applied to marine renewables. A comprehensive review of CBM methods for marine renewables, with an emphasis on fault diagnosis and prognosis techniques, is provided in [33,87]. A number of recommendations and remarks for the performance monitoring of tidal and wave energy converters include considerations on the monitoring of the resource, i.e., upstream flow velocity for tidal devices and sea states for wave devices.

\subsubsection{Novel Tools and Approaches}

There are substantial efforts to develop novel methods and tools to support the ORE O\&M sector. For example, the ROMEO project [88], aims at implementing a Cloud and Internet of Things (IoT) platform to provide real-time diagnosis and prognosis, as well as novel, modern and low-cost CM systems, for the main mechanical and structural components of offshore wind turbines. 
An emerging development is the use of so-called inspect-and-repair robots. For example, BladeBUG [89] is a crawler robot able to climb and walk on turbine blades, while scanning the surface in search of defects and signs of deterioration, and able to perform repairs if needed. In this way, blade inspections and repairs by means of technicians are avoided.

Similarly, the use of drones and autonomous vessels [90] is steadily increasing for offshore wind farm inspection and repair activities. The former can be used to monitor different sections of the tower and the nacelle, including the blades, often avoiding the need to shut down the device. The latter are more suited for visual inspection of foundations (both fixed and floating) or underwater parts of the device. An example of this application is the Watereye project [91], which aims at deploying a network of drones with embedded ultrasound sensors to obtain accurate structural health monitoring of offshore wind devices.

If necessary, both kinds of devices can be equipped with additional instrumentation, e.g., non-destructive sensors such as infrared cameras and laser scanners. Besides, these technologies can be combined for remote evaluation of the assets, e.g., by sending an autonomous mothership to the offshore location from which, once on-site, drones are deployed for inspection or repair. This possibility is being investigated within the MIMRee project [92], a cross-sector programme looking at improving the capabilities of unmanned robots. In this way, operations are accelerated and costs are saved, and accessibility to locations potentially unreachable by human operators is enabled. An updated list of robots and autonomous systems under development specifically for the ORE sector is available at [93]. Pictures of an inspection drone under development within the MIMRee project [92], BladeBUG [89] and an unmanned surface vehicle (USV) for autonomous survey operations [94] are shown in Figure 6.
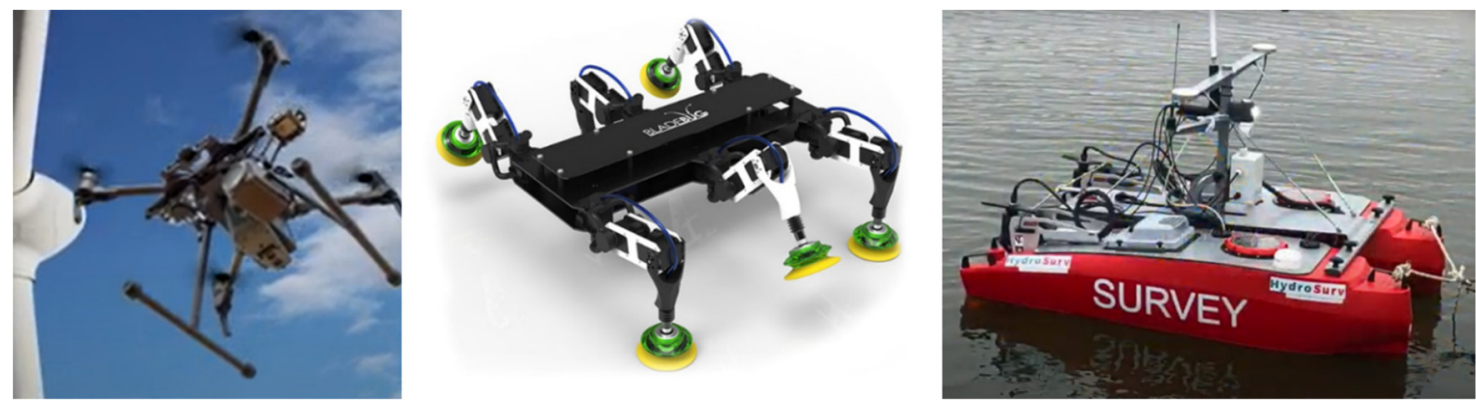

Figure 6. Pictures of an inspection drone under development within the MIMRee project [92], BladeBUG [89], and an unmanned surface vehicle (USV) for autonomous survey operations [94]. Courtesies of MIMRee, BladeBUG and HydroSurv respectively.

Through digitalisation, these innovative systems can be integrated with software and visualization solutions to facilitate the work of operators. A dynamic representation of a system can be obtained through a so-called "digital twin". This is a high-fidelity model which describes an object and its environment in a binary format and renders it in a digital space to analyse possible outcomes and support decision making [95]. For example, digital twins of an ORE device or a maintenance vessel can provide the possibility of visiting the asset remotely (digital walk-trough), with additional information displayed on the virtual reality device used for the inspection. In this way, maintenance is simplified and decision making expedited. Moreover, real-world equipment translated into a realistic digital model provides opportunities for training and immediate access to technical and operational data. An example of digital twins in the ORE sector is explored within the EU project MooringSense [96], aiming at developing a digital replica of the mooring system of floating wind turbines. This will be built by integrating real motion sensors with numerical models and simulation tools, allowing one to obtain parameters such as mooring line tension and degradations state in real time. 
The HOME Offshore project [97] aimed at combining drones for the robotic inspection of offshore wind turbines with artificial intelligence to analyse fault patterns and physics modelling to predict the remaining lifetime. Similarly, the ORCA Hub [98] aims at exploiting robotic systems and artificial intelligence algorithms to interlink the initial mapping and surveying of the device and the subsequent planning and management.

Although these tools and robots aim at reducing the risks to and costs of technicians, currently human supervision is still required to control most interventions. Innovations like the Internet of Things can reduce this burden [99].

\subsection{Diagnosis and Prognosis}

If data on the process that led a component to break down are available, these can be used to understand the failure mechanisms. Diagnosis is used to analyse the differences between normal operating conditions and the degraded state. Hence, prognosis is used to predict when the component is approaching failure. In other words, diagnosis and prognosis use mathematical models to define the relationship between fault causes and fault mechanisms [75]. Mathur et al. [100] define diagnosis and prognosis as processes for the assessment of the past, present and future health of a system. Diagnosis is an assessment of the current (and past) health of a system based on observed data and available knowledge, whereas prognosis is an assessment of the future health.

Kang et al. [83] describe diagnosis and prognosis as the processes used to map the $\mathrm{CM}$ information and to predict the future conditions of the machine, respectively. Two main approaches are identified for diagnosis purposes. The first uses statistical analysis to identify a signal that can represent unusual conditions, whereas the second exploits computational techniques able to self-adapt and improve after an initial training phase. Among the most used computational methods are genetic algorithms (GAs), Machine Learning (ML) and artificial neural networks (ANNs). In [41], ANNs are used to evaluate the degradation of OWT components by modelling the relationship between the condition monitoring data, age and life percentage of components.

According to $[44,50]$, the main aim of prognosis is to determine the remaining useful life (RUL) (i.e., before an end-of-life failure occurs) of a component. This is often subject to a large uncertainty due to the stochastic failure behaviour of the component. Nonetheless, this estimation allows for an assessment of the failure probability before an inspection or a planned intervention, providing support in the optimisation of maintenance intervals. Examples of RUL estimation and predictive maintenance are presented in [101,102].

Regarding prognosis, several approaches are distinguished in the literature $[35,44,83,103]$. Prognosis can be generally achieved through a mathematical or physical model of the component (physics or model-based), through pattern recognition in previously extracted data (data-driven), through previous experience with the maintenance of the same component (experience-based), or a combination of these (hybrid). The choice of a prognosis technique over another depends on factors such as the availability of historical data and the difficulty in establishing an accurate model of the system.

A classification of the main approaches for diagnosis and prognosis is shown in Figure 7.

Signal processing techniques are needed to observe variations in the behaviour or performance of a component, and trigger an alarm if needed. Traditionally, time and frequency domain approaches are employed in commercial CM systems [53,75]. If environmental differences and other factors (e.g., wake effects) are taken into account, the status of a device can be evaluated by comparing its performance with that of neighbouring devices. It is important to note that while CM systems are capable of detecting anomalies in the performance of a component, not all failure modes can be accurately captured, and some might be undetected [75]. 


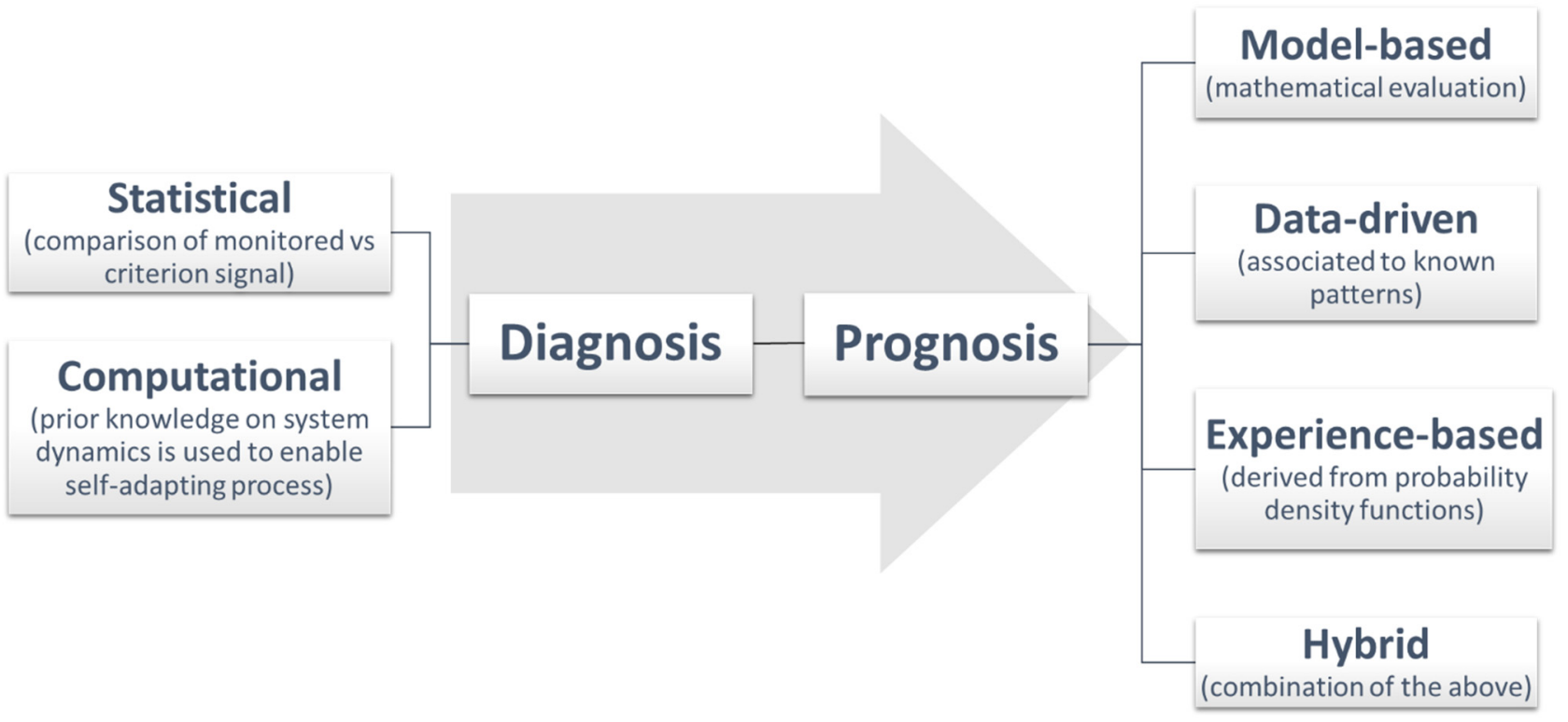

Figure 7. Classification of the main diagnosis and prognosis approaches.

While several techniques can be applied to reveal failure patterns, the main difficulty remains the availability of sufficient and adequate data. If this can be obtained, preprocessing and data quality assurance techniques can be applied to ensure the dataset meets the requirements for failure prognosis. The techniques should also capture causality, other than correlation, between a pattern and the component degradation. A successful example is given in [104], where meteorological conditions (temperature, humidity and wind speed) are directly correlated to the failure behaviour of the five main components of a WT, namely gearbox, generator, frequency converter, pitch and yaw system. A set of both supervised and unsupervised data mining and machine learning techniques is applied to historical data to derive a framework able to predict the imminent failure of the component.

\subsection{Deterioration Models}

Systems operating in dynamic environments are subject to gradual degradation due to both ageing and the effects of a series of external factors or covariates [48]. A framework explicitly showing the influence of covariates on the deterioration process of a system, and how modelling this can support the optimisation of condition-based inspection and replacement policies, is shown in [39]. Degradation can cause either a sudden failure or a reduction in the performance of the component with either incipient (i.e., gradual) or abrupt (i.e., sudden) failures. Thus a deterioration model is required in order to predict the status of the component over time, to set failure thresholds and more generally obtain indications for its maintenance. A systematic review of degradation models and remaining useful life (RUL) estimation is presented in [105-109].

Incipient degradation can be assumed to be continuous (i.e., gradual) or discrete (i.e., in stages), and a corresponding model chosen or implemented based on this assumption. Typical mathematical models for continuous deterioration are the Wiener process $[107,108]$, the Gamma process [107], the inverse Gaussian process [110] and the renewal theory [108]. For discrete state deterioration, typical models are those exploiting the Markovian property, i.e., stochastic "memoryless" processes, where the transition from one state to another depends only on the current state and not on the previous series of events. These can be either Markov, semi-Markov (memoryless only at specific instants) or hidden Markov (with unobservable states) models [109,111]. If degradation depends on stochastic covariates (e.g., environmental conditions), a hazard rate model is the most appropriate, with the proportional hazard model (PHM) being among the most used [105,112]. A complete review of degradation models is provided in [113]. 


\section{Maintenance in Other Industries}

According to the scientometric review presented in [114], artificial intelligence and related techniques are seen as the present and future in the operation and maintenance of wind turbines. This section reports on approaches that have been used in different industries and that could potentially be applied in the ORE sector, especially in the fields of condition-based maintenance, performance assessment and optimisation. In addition, examples of current applications in the offshore wind sector are provided.

In the automotive, aerospace and other industries, CBM has acquired an increasingly important role in preventing faults and increasing availability. Typical large-scale industrial maintenance activities that have been recognised as critical and inevitable fall into the category of "major overhauls, outages, shutdowns, and turnarounds (MoOSTs)". In [115], these activities are investigated in terms of the barriers to knowledge management and experience transfer which might limit their efficient execution. Appropriate solutions are identified in the integration and application of failure analysis approaches, such as fault tree analysis (FTA) [116] and reliability block diagrams (RBDs) [117], alongside multi-criteria decision analysis techniques, such as analytical hierarchy process (AHP) [118].

In [13], it is demonstrated that performance and CM alone are not enough to make sound and informed engineering decisions on maintenance and asset management. Activities such as a clear alignment of the organisational objectives (including asset design, operation, decommissioning, disposal and renewal) and a complete lifecycle assessment are required to obtain a systematic framework for the management of critical industrial assets. Failure and reliability analysis are the core of the framework, accompanied by routine plant-based audits and performance and suitability evaluation of the proposed measures. Statistical data are also exploited to prioritise maintenance actions, together with lifecycle cost analysis to identify the materials and spares required.

In [16], a dynamic predictive maintenance policy is developed by taking into account information on the degradation of the system which is regularly updated. In this way, the maintenance planning is continuously adapted to generate decisions depending on the current state of the system. This kind of framework is defined as a dynamic model acting on a rolling horizon, as opposed to a stationary model acting on an infinite horizon, i.e., assuming long-term stable situations [119]. The framework is demonstrated through a numerical example assuming a system with three components, showing savings in the maintenance cost per unit time against conventional maintenance policies, and implying that it could be extended to a generic multi-system and multi-component level.

An example of intelligent approaches for predictive maintenance, based on the data mining and Industry 4.0 concepts introduced in the next sections, is presented in [120]. Here, a fault diagnosis and prognosis framework, moving from the initial sensor selection to the final decision support and maintenance implementation, is applied to generic machine centres (i.e., milling or drilling machines). In order to achieve intelligent maintenance management, five steps are implemented:

1. Appropriate sensors to monitor the machines are selected together with a suitable data acquisition system.

2. Cleaning, integrations, reduction and transformation techniques are used to preprocess the data produced by all the sensors. This ensures that the data volume is reduced to the relevant parts.

3. Data mining is used in combination with model-based techniques for fault detection, classification and prediction.

4. A diagram of the key performance indicators describing the situation and health condition of the equipment is produced for performance evaluation. Maintenance planning can thus be proposed by using optimisation techniques, e.g., evolutionary algorithms (genetic algorithms, particle swarm optimisation, ant colony optimisation, bee colony algorithm, etc.). 
5. Maintenance is implemented according to the selected strategy. The effects of data and decisions, until now transmitted and elaborated only virtually, are now transferred back to physical systems in the real world.

A thorough and in-depth review of the methods and techniques for decision-making support in industrial maintenance is provided in [45]. Several areas related to maintenance management and planning are identified, including multi-level (e.g., subsystem and component levels) and multi-state (e.g., degradation) systems optimisation, as well as monitoring, prognosis and reliability frameworks. The study finds that CM is the most widespread maintenance policy in the literature reviewed and suggests that the integration of monitoring technologies with modern computational capabilities can enable a transition towards autonomous self-diagnosis and maintenance.

An intelligent condition monitoring and decision support tool for the management of safety-critical situations in offshore oil and gas platforms is developed in [121]. The tool is based on simulated training due to the lack of suitable data in the literature, a common issue also in the ORE sector. In this work, a dynamic model fully representative of a real production process is implemented. Thus, operational conditions with subsequent fault scenarios and maintenance activities are simulated to generate training data. These are used to train monitoring models which allow for online real-time fault detection and identification by means of principal component analysis (PCA) [122]. This demonstrates that if an accurate computational model of the system can be reproduced, then CBM can be effectively integrated into the O\&M strategy without explicit data from a real existing device. To some extent, this can also be interpreted as a digital twin.

\subsection{Soft Sensors}

Soft sensors is another important concept, already applied in other industries, that may provide a significant contribution to the monitoring and CBM of offshore renewables. These, also known as virtual or inferential sensors, are evaluation models able to replicate a measurement signal which does not originate from existing instrumentation, but can still be used as a source of data to monitor, analyse and control a process and detect an imminent fault. In other words, soft sensors make reference to hardware-generated signals and system knowledge to simulate the monitoring of a parameter which would be too difficult or too expensive to monitor directly through a real sensor. The limitations in the use of actual instrumentation might be due to technological constraints, extreme conditions, a harsh environment, lack of space, economic factors or a combination of these. The use of soft sensors can be interpreted as an indirect measurement of a parameter in order to obtain higher quality and/or lower cost estimates of the system status. An advantage of soft sensors is that the variable monitoring can be achieved either offline and at low sampling rate or, if the predictive model is sufficiently quick and accurate, online and at high sampling rate. For example, the temperature in a component which is difficult to reach might be estimated by interpolating the temperature at different points and making use of a model able to establish the correlations between those points and the location of interest. Alternatively, in the case of a mooring system, motion sensors tracking geographical coordinates could be used instead of load cells to monitor the environmental loadings on the system once the motion-loads response is calibrated. A selection of articles describing soft sensors' application in various industries is provided in [123]. A generic implementation of soft sensors is summarised in Figure 8.

In [124], the characteristics of industrial processes in which soft sensors can be applied are discussed, together with a review of case studies showing their application in various industries. Similarly, advanced control and optimisation techniques exploiting readily available process variables for the monitoring of difficult-to-measure variables are reviewed and discussed in [125]. 


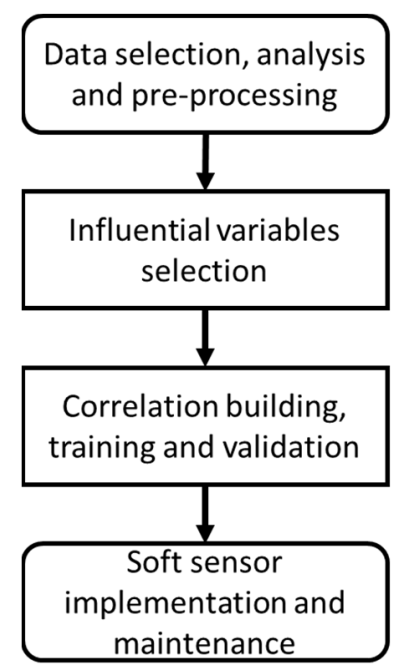

Figure 8. Workflow of a soft sensor implementation. Adapted from [124].

Depending on the approach used to model the relationship between original and simulated signal, soft sensors can be divided in two main categories [126]. Model-driven signals use first principles (physical processes) regulating the dynamics of the variable of interest, whereas data-driven soft sensors are trained through historical data. A third option consists in a mixed approach. In [126], a review of common approaches to implement soft sensors is provided together with a critical analysis of the main issues which prevent an extensive use in various industrial sectors. In [127], guidelines for the successful application of soft sensors are provided together with a series of case studies on industrial applications showing their contribution to the monitoring process.

\subsection{Data Mining, AI and Robotics}

Data mining (DM) is a process which aims at discovering patterns and regularities in large datasets with the final goal of extracting knowledge from these [128]. These patterns can then be used to determine a trend, verify a hypothesis, establish correlation or causality with other datasets, or simply to increase the understanding of a system. The data can converge from multiple sources, and if analysed in real time, can provide immediate decision-making support. A comprehensive literature review and classification methods for data mining techniques can be found in [129]. Data mining techniques are divided into three main branches: statistics, machine learning and artificial intelligence (AI) [120,130].

The first is widely based on the use of statistical models and mathematical functions, to analyse the behaviour of a certain phenomenon which cannot be described in a deterministic way. Measures of fit and suitability of the inferred parameters are usually needed for validation of the models. An example of data mining applications for the improvement of offshore wind turbine O\&M is provided in [131], where autoregressive models and artificial neural networks are compared based on a data mining approach to improve the prediction of weather windows for offshore access and maintenance scheduling.

Machine learning (ML) is based on the implementation of models and algorithms which can improve their predictive performance automatically as more data become available. In order to achieve this, the models have to be "trained" with an initial dataset in order to "learn" how to predict the outcome. Three main classes of ML methods exist: supervised, unsupervised and reinforcement [132]. In the former, data are initially labelled or allocated according to a certain criterion, which sets the desired correlation between inputs and outputs. The model learns the predictive mapping between a set of features and a continuous or categorical outcome. In the unsupervised case, a clear distinction or classification cannot be initially identified in the dataset; hence its structural characteristics or any inferences have to be uncovered using appropriate methods, e.g., clustering or dimensionality reduction. In reinforcement ML, reward mechanisms are set to drive the 
algorithm to learn how to achieve the desired goal. The spider chart in Figure 9 summarises the three main ML categories with related techniques and possible applications [133]. A supervised approach is usually preferable in CM and SHM applications because it allows for a classification and quantification of the damage, whereas an unsupervised model allows only for its identification [57]. To some extent, statistics and ML are closely connected, and there is not a full distinction between the two.

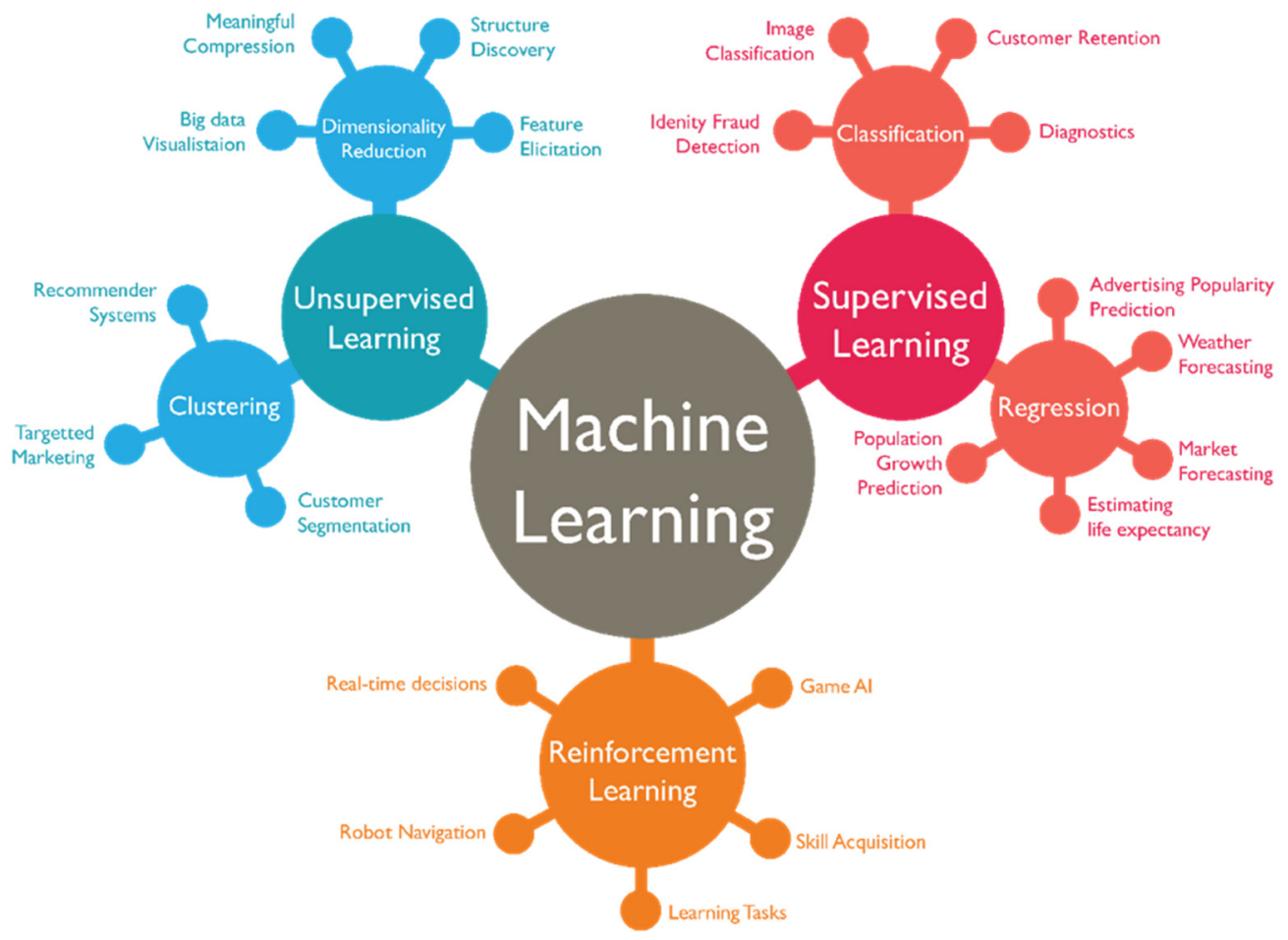

Figure 9. Main machine learning categories, techniques and typical applications [133].

Artificial intelligence (AI) is a generic term which includes a large number of algorithms and methodologies mimicking human- or nature-inspired behaviours to achieve a goal [134]. It can be considered as the ability of computers and machines to solve problems akin to intellectual human capabilities [128]. Systems equipped with AI are able to analyse data and learn from them in order to improve their capabilities. AI includes a range of techniques which support the development of intelligent behaviour in computers and machines. Typical techniques directly linked to AI are heuristics, optimisation algorithms, search functions, artificial neural networks and fuzzy-logic systems. According to [135], $\mathrm{AI}$ is needed in the O\&M of offshore wind turbines to add accuracy and robustness to fault detection algorithms, since SCADA-based monitoring provides low resolution and uncertainty in distinguishing between actual and false faults. An effective data-driven predictive model for the fault prediction of offshore wind turbines is presented in [136]. Another example of AI applications in the offshore wind sector is provided in [23], where evolutionary algorithms are implemented for the multi-objective optimisation of the O\&M assets of an offshore wind farm.

A technique closely related to DM is text mining, since it has an analogous scope (i.e., to extract information) but using words in a text instead of numbers in a dataset. An example of text mining (exploiting ML) applied to the CBM of renewable devices is provided in [34]. Text mining is used to automate, expedite and improve the examination of the service history of wind turbines. In this way, the condition of the device is assessed with results close to human labelling, but in a faster and more systematic way. 


\subsection{Industry 4.0}

Industry 4.0 is the fourth industrial revolution (The first industrial revolution is considered the one in which machines were initially used instead of purely manual or animal work. The second industrial revolution starts with the rationalization of work in industry, using conveyor belts and assembly lines. The third industrial revolution is based on the introduction of computers and industrial robots, or more in general, IT technology [1]). Industry 4.0 indicates the industrial revolution exploiting intelligent information and communication technology (ICT) to create a network of real and virtual devices embedded together. It is also known as "smart (or intelligent) manufacturing", and is closely related to technological concepts such as machine-to-machine (M2M) communication, cyber-physical systems, Internet of Things and Internet of Services, cloud computing and DM $[120,137]$. Industrial machines are equipped with smart components, enabling them to communicate and interact among themselves as well as with external tools and equipment. Every object, product, or service is uniquely identified by a centralized system, and monitored and managed through a common network by means of sensors and actuators. DM techniques are used to store and process the large amount of data collected, while the services offered by various suppliers are coordinated using the internet. Thus, the capabilities of the physical world are expanded via a combination of novel computation, communication and control capabilities [138]. A virtual extension of the real world, in which decisions are taken, is achieved. According to [139], transition into an Industry 4.0 system involves seven design principles:

- Interoperability, amongst real-virtual (cyber-physical) systems and humans;

- Virtualization, of plant and machine models;

- Decentralization, to enable decisions at different levels;

- Real-time capability, to analyse and process data instantaneously;

- Service orientation, to tailor products according to the customer preferences;

- Modularity, to allow for flexibility and easy adaptation to changing conditions; and

- Security, to guarantee safe and secure transmission of private data.

In this way, predictive maintenance is automated, allowing for prompt, intelligent and effective decision making. Also in this case, the transferability to the ORE sector is more than plausible. A network of purpose-built monitoring systems could be used to remotely provide performance or reliability indicators, allowing continuous health monitoring of the device. Hence, ICT and M2M technologies could inform life O\&M operation activities, and a process control system could be used to trigger automated interventions by means of inspect-and-repair robots, drones and autonomous systems such as those identified in Section 3.4.4.

\subsection{IoT and Big Data}

The Internet of Things (IoT) connects systems and devices with people and data processes, allowing for continuous communication and fast computation, and enabling real-time, automated and optimised decision making [140,141]. The different constituents of a system (e.g., an ORE farm) can communicate among themselves to facilitate services and improve the management of the system. Hence, in an offshore wind farm, IoT applications would allow real-time remote control to facilitate turbine access while improving safety for the operators. The IoT progress, application and possibilities have been reviewed with respect to general industrial applications [142,143], emerging technologies such as 5G networks [144] and the energy sector $[140,145]$. In order to be successfully implemented, an appropriate network of sensors, actuators and communication technologies, together with adequate data storage and data processing facilities, is needed. These elements are chosen depending on the application, e.g., the operational and environmental parameters to be monitored, the actions to be taken, power consumption and communication range. For instance, in the case of offshore renewables, wireless communication technologies able to transmit at long distances and characterised by low power consumption are required. 
Examples of this are Long Range (LoRa) [146], Sigfox [147] and Long Term Evolution for Machine-Type Communications (LTE-M) [148].

Another important aspect of IoT is the management of the generated data. These are often indicated as "Big Data" due to their substantial volume, variety and complexity [149]. In the offshore wind sector, due to the increasing volume of performance monitoring and component health indicators, as well as the inclusion of vessel parameters during live operations, Big Data systems can provide significant advantages in the collection, scaling and predictability of data when compared to traditional (e.g., spreadsheet) databases. As a consequence, innovative computational and organisational techniques such as cloud and fog computing are needed. In the first, data are streamed and stored in "the Cloud", i.e., remote servers and data centres but accessible via the internet [150]. In this way, significant and cost-effective data storage and processing capabilities are obtained. Fog computing [151] is an extension of cloud computing, which exploits any device capable of storing, processing and transmitting data (e.g., computers and routers) and which is physically closer to the network. In this way, the network becomes more secure and the overall data management faster.

\section{Discussion}

A number of established and innovative solutions for ORE devices O\&M have been investigated, together with techniques currently used in other industries but with the potential to be applied also in the ORE sector. In this section, these methods are discussed taking into account the different perspectives of various stakeholder categories, namely a farm owner, a technology developer and a maintenance contractor.

A farm owner aims mainly at maximisation of the profitability, and should prefer a holistic approach able to optimise several aspects at once, including risks reduction. For this reason, maturity of the technology and potential for cost reduction will be favoured, together with solutions that are practical to implement and easily extendable to a large number of devices. Although the use of CM is consolidated in the ORE sector, a number of challenges remain in the integration of $\mathrm{CM}$ systems with automation and controller systems. Meaningful organisation of the information retrieved from different sources is required to obtain an understanding of the asset with a single scrutiny, instead of different and separated analyses which do not necessarily provide the full picture. The technological challenges and additional expenses caused by the integration of sensing and communication instrumentation, and the consequent increased energy consumption, as well as the creation of standards and protocols to collect, store and process data, must be taken into account. In this regard, while trade-offs exist between accuracy of fault prediction and additional costs of sensors, the use of operational data collected through SCADA can improve diagnosis and prognosis at no extra cost [22]. Besides, solutions to power the sensors and to deliver the signal are needed for an effective implementation of CM systems. In this regard, cabled solutions would be easier to maintain due to power requirements, but wireless solutions are more practical for non-invasive monitoring. Energy management solutions to guarantee continuous data collection and transmission are also an important aspect of this integration. While most CM systems are based on NDT techniques, the progress in monitoring electrical components and control systems has been slower and component specific.

A maintenance contractor will look mainly at the feasibility and practicality of the O\&M solution, preferring solutions that are simple, effective and safe to deploy. For instance, in offshore wind turbines, the harsher environment, remote location and increased complexity in accessibility make the application of novel technologies more challenging compared to their onshore counterparts. However, as shown in the works reviewed for this paper, these limitations are additional reasons to justify the adoption of modern computational approaches in the O\&M of offshore wind farms. Risk minimisation (health and safety) is the utmost priority, but the business is focused on reaching pre-contracted reliability, availability and maintainability (RAM) targets. Robots will play an increasingly 
important role in producing easier, safer and more productive maintenance practices for offshore renewables. Currently, a mix of fully autonomous (i.e., able to work independently) systems and technologies requiring manual support (remote control) is considered the most appropriate approach at this stage. As the use of automation increases and maintenance management becomes digitalised, suitable measures are needed to ensure that vulnerable processes, the equipment and the generated data are resilient and protected. This creates the need for new requirements in cybersecurity and good practices in the offshore sector, governed by data sharing and collaboration among operators. The ORE Catapult is currently addressing these issues by promoting a "Wind Digital Innovations Forum" [152]. Blockchain $[153,154]$ is another novel technology that can offer support in this topic, by providing a decentralized, verified and secure way of handling the exchange of data and information. These actions can be summarised as the creation of a digital supply chain which guarantees the effective and successful generation, transmission and elaboration of data. The most needed data types in this context will be those related to the current and expected reliability of the various components. However, even if deterioration and RUL can be precisely estimated, and therefore the right time for maintenance accurately identified, other factors like supportability and accessibility have to be taken into account. These restrictions assume higher importance as the distance from shore increases, because the opportunities for maintenance will be narrowed down to fewer weather windows. On a related note, although sensors and other instrumentation can provide valuable support in establishing adequate maintenance and inspection intervals, the accurate assessment of other resources, e.g., materials and labour, remains fundamental in order to establish the optimal maintenance framework.

Technology developers want to propose innovative solutions aiming at impact maximisation, actively involving industry and academia and investing in those solutions with greater potential for cost reduction or RAM increase. Intelligent predictive maintenance relies on a series of innovative techniques which build the fundamentals of Industry 4.0. These techniques, e.g., AI, DM and IoT, need to be further investigated and developed according to the specific requirements of the ORE sector. The benefit of data mining techniques and Big Data lies in the more effective and efficient use of existing and additional data streams, in order to establish and utilise the relationships between the environment, operation, performance and reliability of offshore wind assets. The challenge in the specific application will be to decide which part of the data stream is processed at the edge (e.g., wind speed is typically recorded and $10 \mathrm{~min}$ averaged at the turbine) or streamed to the data centre and computed there. An effective dashboard and alert system will be important to enable the overview of the asset status and the prioritisation of O\&M tasks.

Another important aspect in this regard is the reliability of the data collection network. Recently, due to the Covid-19 pandemic, weather forecast accuracy has significantly decreased due to the loss of the data provided by commercial aircraft, on which weather models rely for their calibration [155]. Similarly, since prognostic models rely on the data from the ORE project, inaccessibility to data due to any sort of prolonged disruption in the collection and transmission network would negatively impact the automated decision making. Maintenance operations might be anticipated or delayed, or human intervention required. Thus, redundancy and reliability of sensing and transmission devices under unexpected situations are important to transition to an automated O\&M model. Soft sensors provide a valuable alternative to the purchase and installation of hardware instrumentations. As long as real-time measurements can be taken from a different source and a representative correlation and estimation algorithm is implemented, the use of soft sensors can open a wide range of possibilities in the condition monitoring scenarios. Several classifications and ramifications exist for modern techniques of machine automation and intelligent algorithms. The boundaries between one field and the other, as well as the links between topics such as AI, ML, DM and statistics, are not well defined. The choice of one methodology over the other, or a combination of them, is problem and constraint specific. 
The increased use of innovative digital and data-based techniques, in the renewables sector, is part of the "energy digitalisation" [156]. Three main branches of digitalisation are shaping the energy sector. These are graphically summarised in Figure 10, and to different extents are all transferable to the ORE sector, either directly or after adaptation.

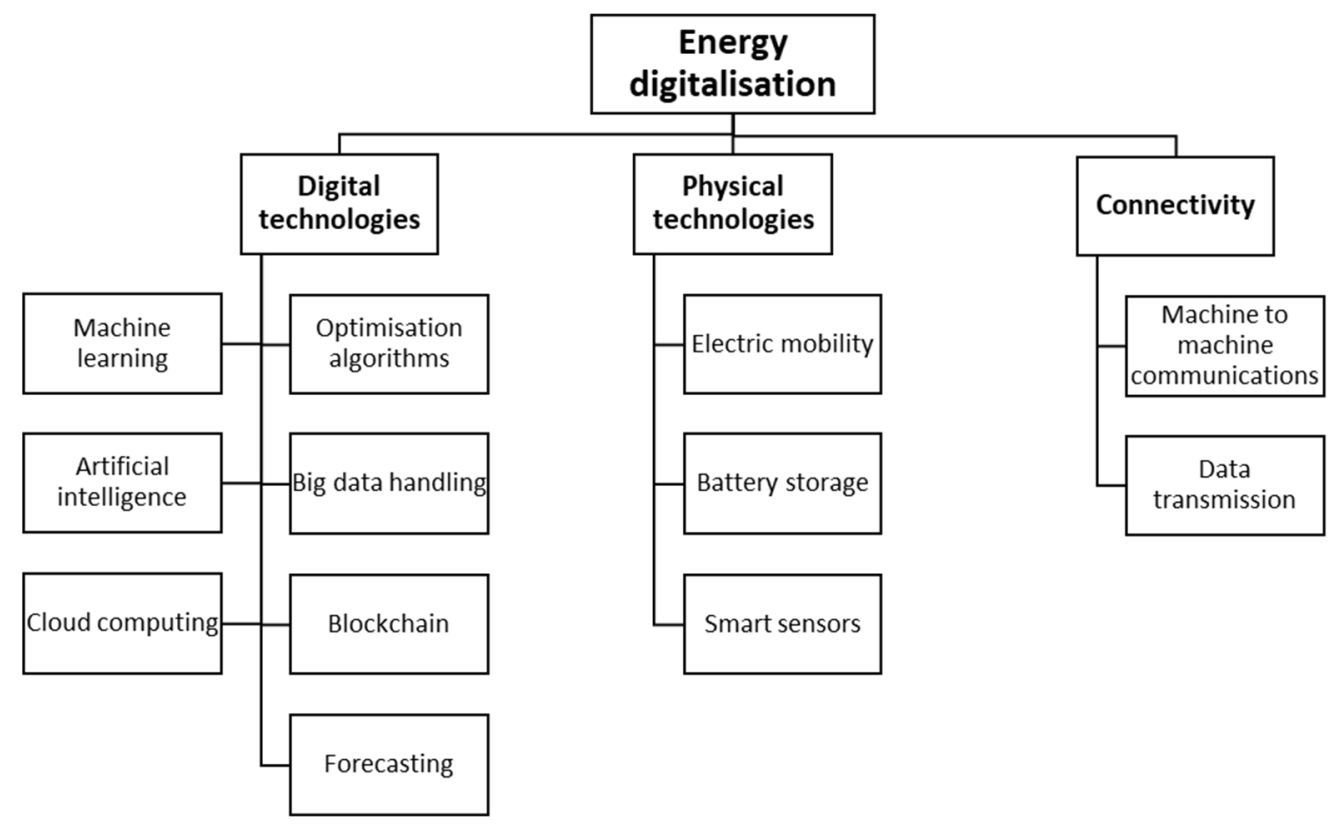

Figure 10. Technological changes defining the shift towards energy digitalisation. Adapted from [156].

In the light of these considerations, the methods and technologies investigated throughout the paper have been ranked against a range of eight categories in order to assess innovative solutions and obtain recommendations for stakeholders in the ORE sector. The outcomes of this ranking (in a score of 1-5, where $1=$ lowest contribution and $5=$ highest contribution to the selected category) are shown in Figure 11. It should be noted that a high score is not necessarily positive (e.g., investment), and as such, an aggregated score is not calculated. Anyhow, comparing different technologies on the basis of a single score would be limiting because these act on different aspects of the O\&M support and should be seen as complimentary to each other (provided case-specific feasibility) rather than competing.

\begin{tabular}{|c|c|c|c|c|c|c|c|c|c|c|}
\hline Category & Method / Technology & & tticality & Maturity & Complexity & $\begin{array}{c}\text { Suitability } \\
\text { to ORE }\end{array}$ & $\begin{array}{c}\text { Investment } \\
\text { needed }\end{array}$ & $\begin{array}{c}\text { Industrial } \\
\text { participation }\end{array}$ & $\begin{array}{c}\text { Potential } \\
\text { (Cost } \\
\text { reduction) }\end{array}$ & $\begin{array}{c}\text { Potential } \\
\text { (RAM* } \\
\text { Increase) }\end{array}$ \\
\hline \multirow{4}{*}{$\begin{array}{l}\text { Traditional } \\
\text { technologies }\end{array}$} & Mathematical models & n & 4 & 5 & 馬 & 馬 & 1 & 1 & In 3 & - \\
\hline & Computational tools & 4 & 5 & 4 & 勻 & 4 & 3 & 4 & 勻 & 3 \\
\hline & Condition monitoring & -4 & 3 & 4 & 3 & 4 & 5 & 5 & 戓 & 5 \\
\hline & Condition-based maintenance & -1n & 3 & 3 & 5 & 5 & 3 & 4 & An & 5 \\
\hline \multirow{4}{*}{$\begin{array}{c}\text { Physical } \\
\text { technologies }\end{array}$} & Inspect-and-repair robots & -1n & 3 & 2 & H] & 5 & 4 & 5 & 戓 & $-\sqrt{n}$ \\
\hline & Drones & 步 & 3 & 4 & 4 & 4 & 2 & HI & 正 & 些 \\
\hline & Autonomous Vessels & Hind & 2 & 2 & 5 & 4 & 3 & 5 & 3 & -nt \\
\hline & Soft sensors & -4 & 4 & 2 & 4 & 3 & 2 & 4 & 馬 & 4 \\
\hline \multirow{4}{*}{$\begin{array}{l}\text { Digital } \\
\text { technologies }\end{array}$} & Digital Twins & 刑 & 3 & 3 & H & 勻 & -4ी & H & 而 & 5 \\
\hline & Data mining & 正 & 2 & 2 & 5 & 4 & 3 & 4 & 政 & H \\
\hline & Machine learning & Hin & 3 & 4 & Hn & 刑 & |rin & Hin & 馬 & H \\
\hline & Artificial intelligence & 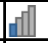 & 2 & 3 & 5 & 4 & 3 & 4 & H & 4 \\
\hline \multirow{2}{*}{ Connectivity } & Internet of Things & - & 2 & 2 & 5 & 3 & 4 & 4 & H & 4 \\
\hline & Big data & nी & 1 & 1 & In & An & -nt & 可 & 馬 & Anll \\
\hline
\end{tabular}

Figure 11. Assessment of the investigated O\&M methods and techniques. * RAM = Reliability, Availability, Maintainability. 
From this table it can be observed that all methods are widely suitable to the ORE sector and require intense industrial participation. Solutions requiring a greater investment are generally more complex and less mature, but also those with the highest potential for cost reduction and RAM increase. Due to their complementarity, one technology should not be favoured over another. Besides, as discussed above, different stakeholders may have different interests. Hence, traditional technologies, which are practical and inexpensive, should be preferred by project managers during the initial phase of a project, e.g., development and consenting. Physical technologies should be of interest to maintenance contractors and asset operators concerned with daily O\&M interventions, improving them with digital technologies once enough experience with the project (i.e., data) has been accumulated. Finally, innovative connectivity solutions should be considered by site managers in order to support the overall O\&M effectiveness.

\section{Conclusions}

As the number of ORE project increases, the O\&M sector evolves to adapt and meet the requirements for cost reduction. Driven by the need to reduce the number of interventions, to improve reliability of the devices and to minimise the O\&M cost, condition-based maintenance is increasingly being adopted. The use of conventional maintenance strategies is enhanced by computational tools. CM instrumentation and improved diagnosis and prognosis techniques, and innovations in automation and robotics are driving further change in offshore O\&M. These innovative methods will change the way in which devices are operated, and more generally, the way in which offshore energy is produced, managed and distributed.

An important insight is that the information derived from CM instrumentation can be integrated into the tactical and strategic planning of the O\&M of an offshore renewable farm, but not directly. A series of numerical modelling techniques are needed to obtain training data for the condition-based planning, in conjunction with a built-on-purpose experimental or computational framework, able to accurately represent the modelled system.

Another finding is that depending on the technology stage of development, different sensors will be chosen for CM purposes. Initially, these could be chosen from off-theshelf solutions to make the implementation more practical. However, once the device is developed, these should be integrated into a single system collecting multiple sources of information, or directly removed once the response of the system to previously monitored phenomena is known. The CM instrumentation should also be updated as more innovative (e.g., cheaper, more reliable, more accurate) technology becomes available.

The long-term vision for the offshore renewables industry involves an almost fully automated asset management system. In this scenario, once the offshore farm is completed and the devices are operated and maintained by autonomous or unmanned vehicles, the decisions made by artificial intelligence and the human supervision is reduced. In this regard, constant manned supervision ("Human-in-the-loop") is expected to remain a requirement to comply with health and safety regulations. In order to achieve this, a multi-disciplinary approach at the interface between robotics, automation, mechatronic, control and human-machine interaction is required. Intelligent predictive maintenance in the ORE sector is a plausible scenario. Various tools have to be integrated into an individual framework, which spans from data collection through multiple sensors to maintenance planning via optimisation techniques. Most importantly, this framework should be continuously updated using real-time collection, elaboration and prediction assessment in order to proactively refine the maintenance decisions according to current constraints and conditions. The physical and virtual worlds need to be deeply interconnected and work in synergy, and Industry 4.0 concepts can support this real-time data stream.

When future research directions are contemplated, artificial intelligence and robotics are still at a preliminary stage of development, and more experience will be necessary to establish the return on O\&M investment in relation to the overall cost savings. Innovations 
in efficient data collection and elaboration methods, together with smart communication systems, are necessary in order to adjust the principles of Industry 4.0 to the ORE sector.

Author Contributions: G.R.: methodology, data curation, formal analysis, visualization, writing-original draft; P.R.T. and L.J.: writing-review and editing, supervision. All authors have read and agreed to the published version of the manuscript.

Funding: The research in this paper received funding from the Supergen ORE Hub ECR Research Fund.

Institutional Review Board Statement: Not applicable.

Informed Consent Statement: Not applicable.

Data Availability Statement: Not applicable.

Acknowledgments: This publication has been supported by the H2020 project FLOTANT coordinated by the Oceanic Platform of the Canary Islands (PLOCAN). The project has received funding from the European Union's Horizon 2020 research and innovation programme under grant agreement No. 815289. The second author acknowledges funding support from the EPSRC Supergen ORE hub [EP/S000747/1].

Conflicts of Interest: The authors declare no conflict of interest. The funders had no role in the design of the study; in the collection, analyses, or interpretation of data; in the writing of the manuscript; or in the decision to publish the results.

\section{References}

1. Renewables Consulting Group. Global Offshore Wind: Annual Market Report. Glob. Offshore Wind Rep. 2020, $2020,130$.

2. Wind Europe. Offshore Wind in Europe-Key Trends and Statistics; Wind Europe: Brussels, Belgium, 2019. [CrossRef]

3. Hannon, M.; Topham, E.; Dixon, J.; Mcmillan, D.; Collu, M.; Topham, E. Offshore wind, ready to float? Global and UK trends in the floating offshore wind market. Glasgow 2019. [CrossRef]

4. Röckmann, C.; Lagerveld, S.; Stavenuiter, J. Operation and Maintenance Costs of Offshore Wind Farms and Potential Multi-use Platforms in the Dutch North Sea. In Aquac. Perspect. Multi-Use Sites Open Ocean Untapped Potential Marine Resources Anthropocene; Buck, B.H., Langan, R., Eds.; Springer International Publishing: Cham, Germany, 2017; pp. 97-113. [CrossRef]

5. Rademakers, L.W.M.M.; Braam, H. OEM aspects of the 500 MW offshore wind farm at NL7 Baseline Configuration; Technical Report DOWEC Report Nr. 10080 rev 2; ECN \& TU: Petten, The Netherlands, 2002; Volume 7.

6. Rinaldi, G.; Thies, P.R.; Johanning, L.; Walker, R.T. A computational tool for the pro-active management of offshore farms. In Proceedings of the 2nd International Conference Offshore Renewable Energy, Glasgow, UK, 19-20 September 2016; pp. 111-115.

7. Tranfield, D.; Denyer, D.; Smart, P. The modern approach to industrial maintenance management. Br. J. Manag. 2003, 14, 207-222. [CrossRef]

8. Dekker, R. Applications of maintenance optimization models: A review and analysis. Reliab. Eng. Syst. Saf. 1996, 51, 229-240. [CrossRef]

9. Lyonnet, P. Maintenance Planning: Methods and Mathematics; Springer Science \& Business Media: Berlin, Germany, 2013.

10. Yamayee, Z.; Sidenblad, K.; Yoshimura, M. A computationally efficient optimal maintenance scheduling method. IEEE Trans. Power Appar. Syst. 1983, 102, 330-338. [CrossRef]

11. De Jonge, B.; Scarf, P.A. A review on maintenance optimization. Eur. J. Oper. Res. 2020, 285, 805-824. [CrossRef]

12. Wang, H. A survey of maintenance policies of deteriorating systems. Eur. J. Oper. Res. 2002, 139, 469-489. [CrossRef]

13. Ayu, K.; Yunusa-Kaltungo, A. A Holistic Framework for Supporting Maintenance and Asset Management Life Cycle Decisions for Power Systems. Energies 2020, 13, 1937. [CrossRef]

14. Takata, S.; Kimura, F.; Van Houten, F.; Westkämper, E.; Shpitalni, M.; Ceglarek, D.; Lee, J. Maintenance: Changing role in life cycle management. Ann. CIRP 2004, 53, 643-656. [CrossRef]

15. Hameed, Z.; Ahn, S.H.; Cho, Y.M. Practical aspects of a condition monitoring system for a wind turbine with emphasis on its design, system architecture, testing and installation. Renew. Energy 2010, 35, 879-894. [CrossRef]

16. Van Horenbeek, A.; Pintelon, L. A dynamic predictive maintenance policy for complex multi-component systems. Reliab. Eng. Syst. Saf. 2013, 120, 39-50. [CrossRef]

17. Lawrence, M.; Anuj, S.M.K.G. Statistical-based or condition-based preventive maintenance? J. Qual. Maint. Eng. 1995, 1, 46-59. [CrossRef]

18. Scheu, M.N.; Tremps, L.; Smolka, U.; Kolios, A.; Brennan, F. A systematic Failure Mode Effects and Criticality Analysis for offshore wind turbine systems towards integrated condition based maintenance strategies. Ocean Eng. 2019, 176, 118-133. [CrossRef]

19. Rinaldi, G. An Integrated Pperation and Maintenance Framework for Offshore Renewable Energy; University of Exeter: Exeter, UK, 2018.

20. Nakagawa, T.; Murthy, D.N.P. Optimal replacement policies for a two-unit system with failure interactions. RAIRO Oper. Res. 1993, 27, 427-438. [CrossRef] 
21. Sheu, S.-H.; Jhang, J.-P. A generalized group maintenance policy. Eur. J. Oper. Res. 1997, 96, 232-247. [CrossRef]

22. Shafiee, M. Maintenance logistics organization for offshore wind energy: Current progress and future perspectives. Renew. Energy 2015, 77, 182-193. [CrossRef]

23. Rinaldi, G.; Pillai, A.C.; Thies, P.R.; Johanning, L. Multi-objective optimization of the operation and maintenance assets of an offshore wind farm using genetic algorithms. Wind Eng. 2019, 1-20. [CrossRef]

24. Rinaldi, G.; Thies, P.R.; Walker, R.; Johanning, L. On the Analysis of a Wave Energy Farm with Focus on Maintenance Operations. J. Mar. Sci. Eng. 2016, 4, 51. [CrossRef]

25. Rinaldi, G.; Thies, P.R.; Walker, R.; Johanning, L. A decision support model to optimise the operation and maintenance strategies of an offshore renewable energy farm. Ocean Eng. 2017, 145, 250-262. [CrossRef]

26. Rinaldi, G.; Thies, P.R.; Johanning, L. A coupled Monte Carlo-Evolutionary Algorithm approach to optimise offshore renewables O \& M. In Proceedings of the 12th European Wave Tidal Energy Conference, Cork, Ireland, 19-20 May 2017; pp. 1-7.

27. Hofmann, M. A Review of Decision Support Models for Offshore Wind Farms with an Emphasis on Operation and Maintenance Strategies. Wind Eng. 2011, 35, 1-16. [CrossRef]

28. Welte, T.M.; Sperstad, I.B.; Halvorsen-Weare, E.E.; Netland, Ø.; Nonås, L.M.; Stålhane, M. Operation and Maintenance Modelling. Offshore Wind Energy Technol. 2018, 269-303. [CrossRef]

29. Seyr, H.; Muskulus, M. Decision Support Models for Operations and Maintenance for Offshore Wind Farms: A Review. Appl. Sci. 2019, 9, 278. [CrossRef]

30. Athanasios, K.; Brennan, F. Deliverable Report D8.1: Review of Existing Cost and O\&M Models, and Development of a HighFidelity Cost/Revenue Model for Impact Assessment. 2018. Available online: https:/ / romeoproject.eu/wp-content/uploads/20 18/12/D8.1_ROMEO_Report-reviewing-exsiting-cost-and-OM-support-models.pdf (accessed on 30 April 2020).

31. Pfaffel, S.; Faulstich, S.; Rohrig, K. Performance and Reliability of Wind Turbines: A Review. Energies 2017, 10, 1904. [CrossRef]

32. Olde Keizer, M.C.A.; Flapper, S.D.P.; Teunter, R.H. Condition-based maintenance policies for systems with multiple dependent components: A review. Eur. J. Oper. Res. 2017, 261, 405-420. [CrossRef]

33. Mérigaud, A.; Ringwood, J.V. Condition-based maintenance methods for marine renewable energy. Renew. Sustain. Energy Rev. 2016, 66, 53-78. [CrossRef]

34. Blanco, M.A.; Marti-Puig, P.; Gibert, K.; Cusidó, J.; Solé-Casals, J. A Text-Mining Approach to Assess the Failure Condition of Wind Turbines Using Maintenance Service History. Energies 2019, 12, 1982. [CrossRef]

35. Peng, Y.; Dong, M.; Zuo, M.J. Current status of machine prognostics in condition-based maintenance: A review. Int. J. Adv. Manuf. Technol. 2010, 50, 297-313. [CrossRef]

36. Castanier, B.; Grall, A.; Bérenguer, C. A condition-based maintenance policy with non-periodic inspections for a two-unit series system. Reliab. Eng. Syst. Saf. 2005, 87, 109-120. [CrossRef]

37. Ahmad, R.; Kamaruddin, S. An overview of time-based and condition-based maintenance in industrial application. Comput. Ind. Eng. 2012, 63, 135-149. [CrossRef]

38. Chen, N.; Ye, Z.S.; Xiang, Y.; Zhang, L. Condition-based maintenance using the inverse Gaussian degradation model. Eur. J. Oper. Res. 2015, 243, 190-199. [CrossRef]

39. Zhao, X.; Fouladirad, M.; Bérenguer, C.; Bordes, L. Condition-based inspection/replacement policies for non-monotone deteriorating systems with environmental covariates. Reliab. Eng. Syst. Saf. 2010, 95, 921-934. [CrossRef]

40. Bouvard, K.; Artus, S.; Bérenguer, C.; Cocquempot, V. Condition-based dynamic maintenance operations planning \& grouping. Application to commercial heavy vehicles. Reliab. Eng. Syst. Saf. 2011, 96, 601-610. [CrossRef]

41. Lu, Y.; Sun, L.; Zhang, X.; Feng, F.; Kang, J.; Fu, G. Condition based maintenance optimization for offshore wind turbine considering opportunities based on neural network approach. Appl. Ocean Res. 2018, 74, 69-79. [CrossRef]

42. De Jonge, B.; Teunter, R.; Tinga, T. The influence of practical factors on the benefits of condition-based maintenance over time-based maintenance. Reliab. Eng. Syst. Saf. 2017, 158, 21-30. [CrossRef]

43. Xu, M.; Jin, X.; Kamarthi, S.; Noor-E-Alam, M. A failure-dependency modeling and state discretization approach for conditionbased maintenance optimization of multi-component systems. J. Manuf. Syst. 2018, 47, 141-152. [CrossRef]

44. Jardine, A.K.S.; Daming, L.; Dragan, B. A review on machinery diagnostics and prognostics implementing condition-based maintenance. Mech. Syst. Signal. Process. 2006, 20, 1483-1510. [CrossRef]

45. Ruschel, E.; Santos, E.A.P.; Loures, E.d.F.R. Industrial maintenance decision-making: A systematic literature review. J. Manuf. Syst. 2017, 45, 180-194. [CrossRef]

46. Amirat, Y.; Benbouzid, M.E.H.; Al-Ahmar, E.; Bensaker, B.; Turri, S. A brief status on condition monitoring and fault diagnosis in wind energy conversion systems. Renew. Sustain. Energy Rev. 2009, 13, 2629-2636. [CrossRef]

47. Cibulka, J.; Ebbesen, M.K.; Hovland, G.; Robbersmyr, K.G.; Hansen, M.R. A review on approaches for condition based maintenance in applications with induction machines located offshore. Model. Identif. Control 2012, 33, 69-86. [CrossRef]

48. Alaswad, S.; Xiang, Y. A review on condition-based maintenance optimization models for stochastically deteriorating system. Reliab. Eng. Syst. Saf. 2017, 157, 54-63. [CrossRef]

49. Marseguerra, M.; Zio, E.; Podofillini, L. Condition-based maintenance optimization by means of genetic algorithms and Monte Carlo simulation. Reliab. Eng. Syst. Saf. 2002, 77, 151-165. [CrossRef]

50. Camci, F. System Maintenance Scheduling With Prognostics Information Using Genetic Algorithm. IEEE Trans. Reliab. 2009, 58, 539-552. [CrossRef] 
51. Rasmekomen, N.; Parlikad, A.K. Condition-based maintenance of multi-component systems with degradation state-rate interactions. Reliab. Eng. Syst. Saf. 2016, 148, 1-10. [CrossRef]

52. Wiggelinkhuizen, E.; Verbruggen, T.; Braam, H.; Rademakers, L.; Xiang, J.; Watson, S. CONMOW: Condition monitoring for offshore wind farms. In Proceedings of the European Wind Energy Conference, Milan, Italy, 7-10 May 2007; Volume 164, pp. 210-219.

53. Yang, W. Condition monitoring of offshore wind turbines. Offshore Wind Farms-Technol. Des. Oper. 2016, 543-572. [CrossRef]

54. Wymore, M.L.; Van Dam, J.E.; Ceylan, H.; Qiao, D. A survey of health monitoring systems for wind turbines. Renew. Sustain. Energy Rev. 2015, 52, 976-990. [CrossRef]

55. Yang, W.; Tavner, P.J.; Crabtree, C.J.; Feng, Y.; Qiu, Y. Wind turbine condition monitoring: Technical and commercial challenges Wind Energy 2014, 17, 673-693. [CrossRef]

56. Hameed, Z.; Hong, Y.S.; Cho, Y.M.; Ahn, S.H.; Song, C.K. Condition monitoring and fault detection of wind turbines and related algorithms: A review. Renew. Sustain. Energy Rev. 2009, 13, 1-39. [CrossRef]

57. Martinez-Luengo, M.; Kolios, A.; Wang, L. Structural health monitoring of offshore wind turbines: A review through the Statistical Pattern Recognition Paradigm. Renew. Sustain. Energy Rev. 2016, 64, 91-105. [CrossRef]

58. García Márquez, F.P.; Tobias, A.M.; Pinar Pérez, J.M.; Papaelias, M. Condition monitoring of wind turbines: Techniques and methods. Renew. Energy 2012, 46, 169-178. [CrossRef]

59. Ghoshal, A.; Sundaresan, M.J.; Schulz, M.J.; Frank Pai, P. Structural health monitoring techniques for wind turbine blades. J. Wind Eng. Ind. Aerodyn. 2000, 85, 309-324. [CrossRef]

60. Smolka, U.; Cheng, P.W. On the Design of Measurement Campaigns for Fatigue Life Monitoring of Offshore Wind Turbines. In Proceedings of the Twenty-Third International Offshore and Polar Engineering Conference, Anchorage, AL, USA, 30 June-5 July 2013 ; p. 6.

61. Devriendt, C.; Magalhães, F.; Weijtjens, W.; De Sitter, G.; Cunha, Á.; Guillaume, P. Structural health monitoring of offshore wind turbines using automated operational modal analysis. Struct. Health Monit. 2014, 13, 644-659. [CrossRef]

62. Ziegler, L.; Gonzalez, E.; Rubert, T.; Smolka, U.; Melero, J.J. Lifetime extension of onshore wind turbines: A review covering Germany, Spain, Denmark, and the UK. Renew. Sustain. Energy Rev. 2018, 82, 1261-1271. [CrossRef]

63. Weijtjens, W.; Verbelen, T.; Capello, E.; Devriendt, C. Vibration based structural health monitoring of the substructures of five offshore wind turbines. Procedia Eng. 2017, 199, 2294-2299. [CrossRef]

64. Wang, P.; Tian, X.; Peng, T.; Luo, Y. A review of the state-of-the-art developments in the field monitoring of offshore structures. Ocean Eng. 2018, 147, 148-164. [CrossRef]

65. Antoniadou, I.; Dervilis, N.; Papatheou, E.; Maguire, A.E.; Worden, K. Aspects of structural health and condition monitoring of offshore wind turbines. Philos. Trans. R. Soc. A Math. Phys. Eng. Sci. 2015, 373. [CrossRef] [PubMed]

66. Nilsson, J.; Bertling, L. Maintenance Management of Wind Power Systems Using Condition Monitoring Systems—Life Cycle Cost Analysis for Two Case Studies. IEEE Trans. Energy Convers. 2007, 22, 223-229. [CrossRef]

67. McMillan, D.; Thöns, S.; May, A. Economic analysis of condition monitoring systems for offshore wind turbine sub-systems. IET Renew. Power Gener. 2015, 9, 900-907. [CrossRef]

68. Cui, Y.; Bangalore, P.; Tjernberg, L.B. An Anomaly Detection Approach Based on Machine Learning and SCADA Data for Condition Monitoring of Wind Turbines. In Proceedings of the 2018 IEEE International Conference on Probabilistic Methods Applied to Power Systems, Liege, Belgium, 18-21 August 2018; pp. 1-6. [CrossRef]

69. Yang, W.; Court, R.; Jiang, J. Wind turbine condition monitoring by the approach of SCADA data analysis. Renew. Energy 2013, 53, 365-376. [CrossRef]

70. Reder, M.D.; Gonzalez, E.; Melero, J.J. Wind Turbine Failures-Tackling current Problems in Failure Data Analysis. J. Phys. Conf. Ser. 2016, 753, 72027. [CrossRef]

71. Gonzalez, E.; Reder, M.; Melero, J.J. SCADA alarms processing for wind turbine component failure detection. J. Phys. Conf. Ser. 2016, 753, 72019. [CrossRef]

72. Gonzalez, E.; Tautz-Weinert, J.; Melero, J.J.; Watson, S.J. Statistical Evaluation of SCADA data for Wind Turbine Condition Monitoring and Farm Assessment. J. Phys. Conf. Ser. 2018, 1037, 32038. [CrossRef]

73. Qiu, Y.; Feng, Y.; Tavner, P.; Richardson, P.; Erdos, G.; Chen, B. Wind turbine SCADA alarm analysis for improving reliability. Wind Energy 2012, 15, 951-966. [CrossRef]

74. Tawn, R.; Browell, J.; Dinwoodie, I. Missing data in wind farm time series: Properties and effect on forecasts. Electr. Power Syst. Res. 2020, 189. [CrossRef]

75. Liu, W.Y.; Tang, B.P.; Han, J.G.; Lu, X.N.; Hu, N.N.; He, Z.Z. The structure healthy condition monitoring and fault diagnosis methods in wind turbines: A review. Renew. Sustain. Energy Rev. 2015, 44, 466-472. [CrossRef]

76. Yang, W.; Jiang, J. Wind turbine condition monitoring and reliability analysis by SCADA information. In Proceedings of the 2011 Second International Conference Mechanic Automation and Control Engineering, Inner Mongolia, China, 15-17 July 2011; pp. 1872-1875. [CrossRef]

77. Artigao, E.; Martín-Martínez, S.; Honrubia-Escribano, A.; Gómez-Lázaro, E. Wind turbine reliability: A comprehensive review towards effective condition monitoring development. Appl. Energy 2018, 228, 1569-1583. [CrossRef]

78. Zhou, A.; Yu, D.; Zhang, W. A research on intelligent fault diagnosis of wind turbines based on ontology and FMECA. Adv. Eng. Inform. 2015, 29, 115-125. [CrossRef] 
79. Tchakoua, P.; Wamkeue, R.; Ouhrouche, M.; Slaoui-Hasnaoui, F.; Tameghe, A.T.; Ekemb, G. Wind Turbine Condition Monitoring: State-of-the-Art Review, New Trends, and Future Challenges. Energies 2014, 7, 2595-2630. [CrossRef]

80. Tautz-Weinert, J.; Watson, S.J. Using SCADA data for wind turbine condition monitoring-A review. IET Renew. Power Gener. 2017, 11, 382-394. [CrossRef]

81. Pliego Marugán, A.; García Márquez, F.P.; Pinar Pérez, J.M. Optimal Maintenance Management of Offshore Wind Farms. Energies 2016, 9, 46. [CrossRef]

82. Nabati, E.G.; Thoben, K.-D. Data Driven Decision Making in Planning the Maintenance Activities of Off-shore Wind Energy. Procedia CIRP 2017, 59, 160-165. [CrossRef]

83. Kang, J.; Sobral, J.; Soares, C.G. Review of Condition-Based Maintenance Strategies for Offshore Wind Energy. J. Mar. Sci. Appl. 2019, 18, 1-16. [CrossRef]

84. Proskovics, R.; Hutton, G.; Torr, R.; Scheu, M.N. Methodology for Risk Assessment of Substructures for Floating Wind Turbines. Energy Procedia 2016, 94, 45-52. [CrossRef]

85. Rinaldi, G.; Thies, P.; Johanning, L.; Mcevoy, P.; Georgallis, G.; Moraiti, A.; Lahuerta, C.C.; Vidmar, M. Informing components development innovations for floating offshore wind through applied FMEA framework. In Proceedings of the 39th Conference Ocean Offshore and Artic Engineering, Fort Lauderdale, FL, USA, 3-7 August 2020.

86. FLOTANT Project. 2019. Available online: http:/ / flotantproject.eu/ (accessed on 22 November 2019).

87. Kenny, C.J.; Findlay, D.; Lazakis, I.; Shek, J.; Thies, P.R. Control and instrumentation topologies for an integrated wave energy array. In Proceedings of the 2nd International Conference Renew Energies Offshore, Lisbon, Portugal, 24-26 October 2016; pp. $405-412$.

88. Iberdrola Renewables. ROMEO Project. 2017. Available online: https:/ /www.romeoproject.eu (accessed on 14 May 2020).

89. BladeBUG, n.d. Available online: http:// bladebug.co.uk/ (accessed on 30 April 2020).

90. Fahrni, L.; Thies, P.; Johanning, L.; Cowles, J. Scope and feasibility of autonomous robotic subsea intervention systems for offshore inspection, maintenance and repair. In Proceedings of the 3rd International Conference Offshore Renew, Energy, Lisbon, Portugal, 8-10 October 2018; pp. 771-778. [CrossRef]

91. CEIT. Watereye Project. 2020. Available online: https: / / watereye-project.eu/ (accessed on 4 June 2020).

92. MIMRee. Multi-Platform Inspection, Maintenance And Repair In Extreme Environments (MIMRee). 2019. Available online: https:/ / ore.catapult.org.uk/stories/mimree/ (accessed on 1 May 2020).

93. ORE Catapult. The Robots Leading the Offshore Renewables Revolution. 2020. Available online: https://ore.catapult.org.uk/ stories/the-robots-leading-the-renewable-energy-revolution/ (accessed on 4 June 2020).

94. HydroSurv. 2020. Available online: https:/ / www.hydro-surv.com/?page_id=1653/\#reav10 (accessed on 5 June 2020).

95. Offshore Energy. Digital Twins for the Maritime Sector. 2020. Available online: https://www.offshore-energy.biz/digital-twinsfor-the-maritime-sector/ (accessed on 20 July 2020).

96. MooringSense Project. 2020. Available online: https:/ / www.mooringsense.eu/ (accessed on 4 June 2020).

97. Project, H. Holistic Operation and Maintenance for Energy from Offshore Wind Farms. 2020. Available online: http:// homeoffshore.org/ (accessed on 1 May 2020).

98. Orca Hub. Offshore Robotics for Certification of Assets. 2017. Available online: https: / / orcahub.org/ (accessed on 1 May 2020).

99. Motlagh, N.H.; Bagaa, M.; Taleb, T. Energy and delay aware task assignment mechanism for UAV-based IoT platform. IEEE Internet Things J. 2019, 6, 6523-6536. [CrossRef]

100. Mathur, A.; Cavanaugh, K.F.; Pattipati, K.R.; Willett, P.K.; Galie, T.R. Reasoning and modeling systems in diagnosis and prognosis. Proc. SPIE 2001, 4389. [CrossRef]

101. Gray, C.S.; Watson, S.J. Physics of Failure approach to wind turbine condition based maintenance. Wind Energy 2010, 13, 395-405. [CrossRef]

102. Lu, S.; Tu, Y.C.; Lu, H. Predictive condition-based maintenance for continuously deteriorating systems. Qual. Reliab. Eng. Int. 2007, 23, 71-81. [CrossRef]

103. Zhang, Z.; Si, X.; Hu, C.; Lei, Y. Degradation data analysis and remaining useful life estimation: A review on Wiener-process-based methods. Eur. J. Oper. Res. 2018, 271, 775-796. [CrossRef]

104. Reder, M.; Yürüssen, N.Y.; Melero, J.J. Data-driven learning framework for associating weather conditions and wind turbine failures. Reliab. Eng. Syst. Saf. 2018, 169, 554-569. [CrossRef]

105. Si, X.S.; Wang, W.; Hu, C.H.; Zhou, D.H. Remaining useful life estimation-A review on the statistical data driven approaches. Eur. J. Oper. Res. 2011, 213, 1-14. [CrossRef]

106. Ye, Z.S.; Xie, M. Stochastic modelling and analysis of degradation for highly reliable products. Appl. Stoch. Model. Bus. Ind. 2015, 31, 16-32. [CrossRef]

107. Van Noortwijk, J.M. A survey of the application of gamma processes in maintenance. Reliab. Eng. Syst. Saf. 2009, 94, 2-21. [CrossRef]

108. Grall, A.; Dieulle, L.; Bérenguer, C.; Roussignol, M. Continuous-time predictive-maintenance scheduling for a deteriorating system. IEEE Trans. Reliab. 2002, 51, 141-150. [CrossRef]

109. Kurt, M.; Kharoufeh, J.P. Monotone optimal replacement policies for a Markovian deteriorating system in a controllable environment. Oper. Res. Lett. 2010, 38, 273-279. [CrossRef]

110. Wang, X.; Xu, D. An Inverse Gaussian Process Model for Degradation Data. Technometrics 2010, 52, 188-197. [CrossRef] 
111. Neves, M.L.; Santiago, L.P.; Maia, C.A. A condition-based maintenance policy and input parameters estimation for deteriorating systems under periodic inspection. Comput. Ind. Eng. 2011, 61, 503-511. [CrossRef]

112. Singpurwalla, N.D. Survival in Dynamic Environments. Stat. Sci. 1995, 10, 86-103. [CrossRef]

113. Gorjian, N.; Ma, L.; Mittinty, M.; Yarlagadda, P.; Sun, Y. A Review on Degradation Models in Reliability Analysis BT-Engineering Asset Lifecycle Management; Emmanouilidis, D., Koronios, C., Mathew, J., Eds.; Springer: London, UK, 2010; pp. 369-384.

114. Chatterjee, J.; Dethlefs, N. Scientometric review of artificial intelligence for operations \& maintenance of wind turbines: The past, present and future. Renew. Sustain. Energy Rev. 2021, 144, 111051. [CrossRef]

115. Iheukwumere-Esotu, L.O.; Yunusa Kaltungo, A. Assessment of Barriers to Knowledge and Experience Transfer in Major Maintenance Activities. Energies 2020, 13, 1721. [CrossRef]

116. Ali Baig, A.; Ruzli, R.; Buang, A.B. Reliability Analysis Using Fault Tree Analysis: A Review. Int. J. Chem. Eng. Appl. 2013, 4, 169-173. [CrossRef]

117. Ebeling, C. An Introduction to Reliability and Maintainability Engineering; McGraw-Hill: Boston, MA, USA, 1996.

118. Al-Harbi, K.M.A.-S. Application of the AHP in project management. Int. J. Proj. Manag. 2001, 19, 19-27. [CrossRef]

119. Dekker, R.; Wildeman, R.E.; van der Duyn Schouten, F.A. A review of multi-component maintenance models with economic dependence. Math. Methods Oper. Res. 1997, 45, 411-435. [CrossRef]

120. Li, Z.; Wang, Y.; Wang, K.-S. Intelligent predictive maintenance for fault diagnosis and prognosis in machine centers: Industry 4.0 scenario. Adv. Manuf. 2017, 5, 377-387. [CrossRef]

121. Natarajan, S.; Srinivasan, R. Multi-model based process condition monitoring of offshore oil and gas production process. Chem. Eng. Res. Des. 2010, 88, 572-591. [CrossRef]

122. Rinaldi, G.; Portillo, J.C.C.; Khalid, F.; Henriques, J.C.C.; Thies, P.R.; Gato, L.M.C.; Johanning, L. Multivariate analysis of the reliability, availability, and maintainability characterizations of a Spar-Buoy wave energy converter farm. J. Ocean Eng. Mar. Energy 2018, 4, 199-215. [CrossRef]

123. Science Direct. Soft Sensor. 2020. Available online: https://www.sciencedirect.com/topics/materials-science/soft-sensor (accessed on 5 June 2020).

124. Kadlec, P.; Gabrys, B.; Strandt, S. Data-driven Soft Sensors in the process industry. Comput. Chem. Eng. 2009, 3, 795-814. [CrossRef]

125. Warne, K.; Prasad, G.; Rezvani, S.; Maguire, L. Statistical and computational intelligence techniques for inferential model development: A comparative evaluation and a novel proposition for fusion. Eng. Appl. Artif. Intell. 2004, 17, 871-885. [CrossRef]

126. Kadlec, P.; Gabrys, B. Soft sensors: Where are we and what are the current and future challenges? IFAC Proc. Vol. $2009,2,572-577$. [CrossRef]

127. Fortuna, L.; Graziani, S.; Rizzo, A.; Xibilia, M.G. Soft Sensors for Monitoring and Control of Industrial Processes; Springer: London, UK, 2007. [CrossRef]

128. Ertel, W. Introduction to Artificial Intelligence; Springer International Publishing: Cham, Germany, 2017. [CrossRef]

129. Siguenza-Guzman, L.; Saquicela, V.; Avila-Ordóñez, E.; Vandewalle, J.; Cattrysse, D. Literature Review of Data Mining Applications in Academic Libraries. J. Acad. Librariansh. 2015, 41, 499-510. [CrossRef]

130. Girija, N.; Srivatsa, S.K. A Research Study: Using Data Mining in Knowledge Base Business Strategies. Inf. Technol. J. 2006, 5, 590-600. [CrossRef]

131. Dinwoodie, I.; Catterson, V.M.; McMillan, D. Wave height forecasting to improve off-shore access and maintenance scheduling. In Proceedings of the 2013 IEEE Power \& Energy Society General Meeting, Vancouver, BC, Canada, 21-25 July 2013; pp. 1-5. [CrossRef]

132. Soraghan, C. Blog Part 1: Machine Learning Use-Cases In The Wind Industry. 2020. Available online: https:/ / ore.catapult.org. uk/blog/part-1-machine-learning-use-cases-in-the-wind-industry/ (accessed on 20 July 2020).

133. Chugh, J. Types of Machine Learning and Top 10 Algorithms Everyone Should Know. 2020. Available online: https://blogs. oracle.com/author/jay-chugh (accessed on 20 July 2020).

134. Russell, S.J.; Norvig, P. Artificial Intelligence: A Modern Approach; Prentice Hall: Upper Saddle River, NJ, USA, 2003.

135. Ren, Z.; Verma, A.S.; Li, Y.; Teuwen, J.J.E.; Jiang, Z. Offshore wind turbine operations and maintenance: A state-of-the-art review. Renew. Sustain. Energy Rev. 2021, 144, 110886. [CrossRef]

136. Koltsidopoulos Papatzimos, A.; Thies, P.R.; Dawood, T. Offshore wind turbine fault alarm prediction. Wind Energy 2019, 22, 1779-1788. [CrossRef]

137. Wang, K.; Wang, Y.; Strandhagen, J.O.; Yu, T. Advanced Manufacturing and Automation; V. WIT Press: Southampton, UK, 2016.

138. Baheti, R.; Gill, H. Cyber-physical Systems. Impact Control Technol. 2011, 161-166.

139. Hermann, M.; Pentek, T.; Otto, B. Design Principles for Industrie 4.0 Scenarios. In Proceedings of the 201649 th Hawaii International Conference on System Sciences (HICSS), Koloa, HI, USA, 5-8 January 2016; pp. 3928-3937. [CrossRef]

140. Hossein Motlagh, N.; Mohammadrezaei, M.; Hunt, J.; Zakeri, B. Internet of Things (IoT) and the Energy Sector. Energies 2020, 13, 494. [CrossRef]

141. Tamilselvan, K.; Thangaraj, P. Pods-A novel intelligent energy efficient and dynamic frequency scalings for multi-core embedded architectures in an IoT environment. Microprocess Microsyst. 2020, 72, 102907. [CrossRef]

142. Da Xu, L.; He, W.; Li, S. Internet of things in industries: A survey. IEEE Trans. Ind. Informat. 2014, 10, $2233-2243$. 
143. Ibarra-Esquer, J.E.; González-Navarro, F.F.; Flores-Rios, B.L.; Burtseva, L.; Astorga-Vargas, M.A. Tracking the evolution of the internet of things concept across different application domains. Sensors 2017, 17, 1379. [CrossRef]

144. Gupta, A.; Jha, R.K. A survey of 5G network: Architecture and emerging technologies. IEEE Access 2015, 3, 1206-1232. [CrossRef]

145. Hui, H.; Ding, Y.; Shi, Q.; Li, F.; Song, Y.; Yan, J. 5G network-based Internet of Things for demand response in smart grid: A survey on application potential. Appl. Energy 2020, 257, 113972. [CrossRef]

146. Augustin, A.; Yi, J.; Clausen, T.; Townsley, W.M. A study of LoRa: Long range \& low power networks for the internet of things. Sensors 2016, 16, 1466.

147. Mekki, K.; Bajic, E.; Chaxel, F.; Meyer, F. Overview of cellular LPWAN technologies for IoT deployment: Sigfox, LoRaWAN, and NB-IoT. In Proceedings of the 2018 IEEE International Conference on Pervasive Computing Communication, Athens, Greece, 19-23 March 2019; pp. 197-202.

148. Lauridsen, M.; Kovács, I.Z.; Mogensen, P.; Sorensen, M.; Holst, S. Coverage and capacity analysis of LTE-M and NB-IoT in a rural area. In Proceedings of the 2016 IEEE 84th Vehicular Technology Conference (VTC-Fall), Montreal, QC, Canada, 18-21 September 2016; pp. 1-5.

149. Chen, M.; Mao, S.; Liu, Y. Big data: A survey. Mob. Netw. Appl. 2014, 19, 171-209. [CrossRef]

150. Joseph, A.D.; Katz, R.A.; Konwinski, A.; Gunho, L.E.E.; Patterson, D.; Rabkin, A. A view of cloud computing. Commun. ACM 2010, 53, 50-58. [CrossRef]

151. Atlam, H.F.; Walters, R.J.; Wills, G.B. Fog computing and the internet of things: A review. Big Data Cogn. Comput. 2018, 2, 10. [CrossRef]

152. ORE. Catapult. Wind Digital Innovations Forum. 2020. Available online: https://cdn2.hubspot.net/hubfs/4351574/8812 _CatapultWindDIForum.pdf?utm_referrer=https $\% 3 \mathrm{~A} \% 2 \mathrm{~F} \% 2$ Fore.catapult.org.uk $\% 2$ Foperation-performance $\% 2 F s t r a t e g i c-$ programmes $\% 2$ Fdata-digital\%2Fwind-digital-innovations-forum\%2F (accessed on 30 April 2020).

153. Hawlitschek, F.; Notheisen, B.; Teubner, T. The limits of trust-free systems: A literature review on blockchain technology and trust in the sharing economy. Electron. Commer. Res. Appl. 2018, 29, 50-63. [CrossRef]

154. Andoni, M.; Robu, V.; Flynn, D.; Abram, S.; Geach, D.; Jenkins, D.; McCallum, P.; Peacock, A. Blockchain technology in the energy sector: A systematic review of challenges and opportunities. Renew. Sustain. Energy Rev. 2019, 100, 143-174. [CrossRef]

155. Freedman, A. The Coronavirus Pandemic and Loss of Aircraft Data are Taking a Toll on Weather Forecasting. Washington Post. 2020. Available online: https:/ / www.washingtonpost.com/weather/2020/05/12/weather-forecasting-coronavirus-flights/?ref= nl-rep-a-bgr (accessed on 12 May 2020).

156. Judson, E.; Soutar, I.; Mitchell, C. Governance Challenges Emerging from Energy Digitalisation; University of Exeter: Exeter, UK, 2020. 